\title{
IN \\ DISEASES OF THE COLON
}

\author{
By \\ Norman P. Henderson, M.B., Ch.B., D.M.R.e. \\ Radiologist, St. Mark's Hospital (for Rectum and Colon), London, E.C.I.
}

With the limited space at my disposal it is not possible to cover in detail the whole field of radiology of diseases of the colon, but I propose to consider some of the appearances that definitely establish disease of the bowel as determined by $\mathrm{X}$-ray examination; some of the difficulties that have to be overcome, and a few of the fallacies that are likely to be encountered in this field of investigation.

As recently as I943, the late Sir Arthur Hurst, great worker in this field of investigation, "warned strongly against X-ray examination as a method of diagnosis" in diseases of the colon. At that time this sweeping statement was challenged in the Correspondence Columns of the British Medical Journal, by a number of writers, including myself. Although Sir Arthur Hurst, then claimed to have been wrongly reported, I felt at that time, as I do now, that there was much truth in his original criticism of radiological work generally on diseases of the bowel, and I cannot do better than quote part of my original letter, B.M.J., August 2I, I943, vol. ii, p. 247.

"At once let me say I have some sympathy with Sir Arthur Hurst, and I have no hesitation in observing that in this country there is probably more inferior work turned out in examinations by the opaque enema than in any other branch of radiology. We do not require to search for the reasons, and two prominent causes for this failure to my mind are outstanding. These are lack of thorough preparation of the patient and incomplete thoroughness of the radiological technique. Mild aperients should be employed for premedication and on no account strong irritant drugs such as castor oil. The latter when used perhaps cause more cases of gas collection and spasm than is generally appreciated. The preliminary 'washout' of the bowel should be done with plain warm water and preferably by the Studa chair method, 'provided a rubber catheter is substituted for the metal variety. The use of metal catheters is to be discouraged in view of the risk of bruising of the rectal wall or actual perforation.' On no account should irritant substances such as soap be included in the 'wash-out.' Since the soap-and-water enema was discontinued at St. Mark's Hospital some years ago cases of spasm of the bowel are rare. As to technique, space does not permit detailing some of the important features, but I would stress the importance of the oblique views and particularly the left oblique view. Time and time again when nothing is found in the straight postero-anterior views an early carcinoma is demonstrated in one of the oblique views. Inflation of the bowel with air after the enema in the majority of cases is of limited value. In early carcinoma it is, in fact, misleading, but in cases of multiple diverticulosis it does further balloon out the sacs of the diverticula and help to clinch the diagnosis.

"During the past fourteen years, while in charge of the X-ray department at St. Mark's Hospital, operative findings on all cases that have been examined by an opaque enema are returned to the department. The records show that out of 2,200 opaque enema examinations only four cases of missed X-ray diagnosis are recorded. Of the four, two were suspected and the enema repeated but the growth not demonstrated. The growth in the third was obscured by a greatly distended bowel; and in the fourth, a double carcinoma on the posterior wall of the sigmoid flexure, the bowel assumed that elastic expansile feature, and kept the growths hidden behind the redundant loops of the pelvic colon even after the administration of the third opaque enema. All these cases were operated upon and the growths removed.

"On the other side of the balance-sheet could be enumerated various cases of how an opaque enema established a diagnosis quite unsuspected clinically; confirmed a clinical suspicion, or corrected a. clinical diagnosis from one of carcinoma to one of diverticulosis, or vice versa. In one case a slowly growing carcinoma was watched from its very earliest stages over a period of three years by a. series of opaque enemata at a few monthly intervals. The growth was eventually removed, and seven years later the patient, a doctor running a large practice, is in perfect health. Apart from 
saving the patient's life the series of examinations was most instructive as to the radiological changes of a very early growth.

"It might therefore be correct to say that the opaque enema is of the greatest value as a diagnostic agent if a positive finding is recorded. On the other hand, if the result is negative, on no account should it be accepted that early pathology has been finally disposed of, but the physician or surgeon must make his final decision as to diagnosis on his other clinical findings."

\section{Preliminary Preparation}

As recorded in the quotation from my letter above preliminary preparation is highly important, and in fact should be regarded almost as important as the actual X-ray examination itself. The present technique as practised at St. Mark's Hospital is for the patient to take mild aperients on two nights before the day of the X-ray examination. If the patient is in the habit of taking an aperient of his, or her own choice, this should continue. If the patient is a subject of diarrhoea then no aperients should be taken, and only the

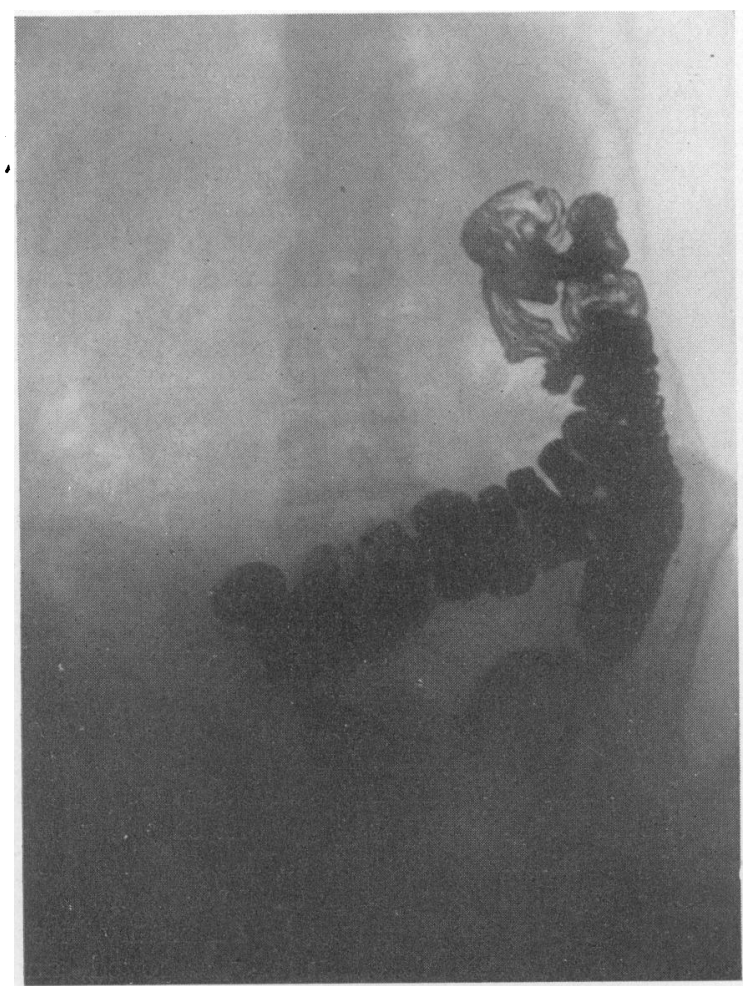

FIG. I.-Without preparation and apparent hold up in the hepatic portion of the transverse colon. "wash-out" of the colon on the actual day of the examination carried out. On the other hand, if no aperients are customary and severe constipation is a feature, two vegetable laxatives are recommended on both evenings before the examination. If moderately constipated, one or two Taxol, or Lixen tablets should be effective. Castor oil and other strong purgatives should be definitely excluded, for reasons stated above. About two hours before the X-ray examination the colon should be thoroughly "washed-out" by a series of plain water enemata, using if necessary up to I/2 pints of water. Clearing of the colon, however, is best carried out by employing the Studa chair method of irrigation, provided, as stated above, a rubber and not a metal catheter is employed, whereby a two-way flow of water in and out of the colon proceeds over a period of about one hour and so more thoroughly cleanses the bowel in readiness for the opaque enema which follows. On no account should a soap and water enema be permitted. Apart from producing abnormal appearances in the bowel resulting from spasm and gas collection, the soap and water enema has been proved to produce small punctuate haemorrhages in the mucosa, and may therefore prove dangerous

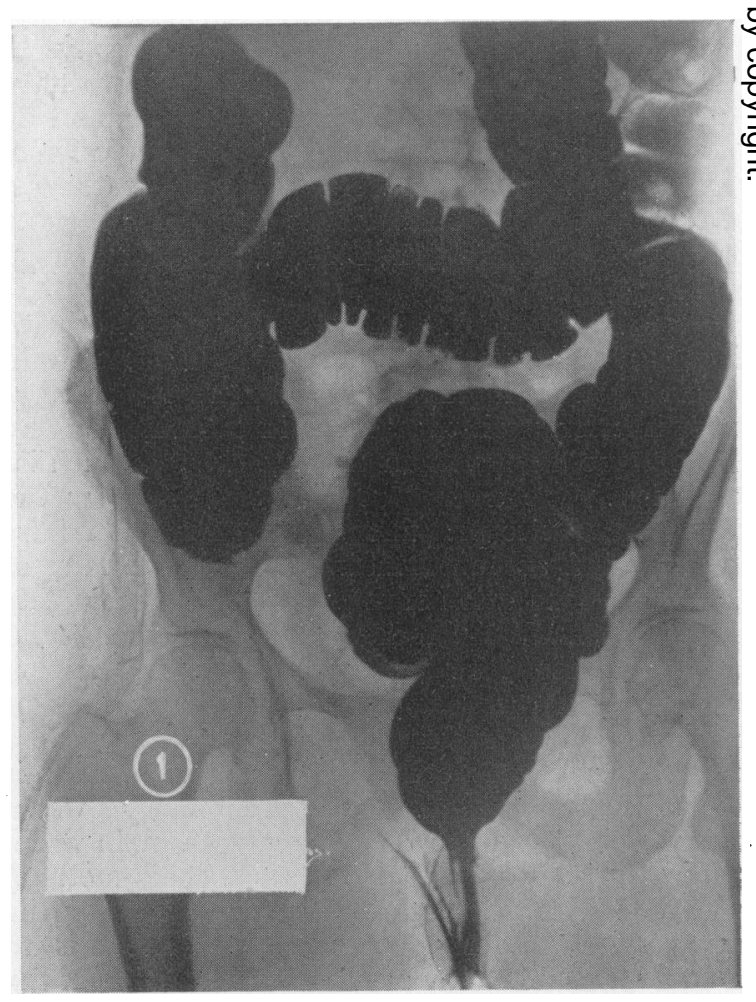

Fig. 2.-After thorough preparation, normal bowel, same colon. 
to the patient. A number of drugs as advocated by various Continental and a few British workers for eliminating gas collection after very thorough trial at St. Mark's Hospital have not proved successful, and their use has been discontinued for preparation of the bowel (see Fig. I and 2).

\section{Preliminary Examinations-Screen and Radiographic}

Before the opaque enema examination is commenced a straight, preliminary or "scout" radiograph of the abdomen should be taken. These preliminary radiographs sometimes reveal renal, ureteric, prostatic calculi, or gall-stones, calcification of arteries of the bowel or otherwise, and occasionally concretions in the appendix of the same density as barium have been seen which otherwise might be more difficult to detect if obscured by the opaque enema. Just before the administration of the opaque enema it has been found a useful preliminary to have a quick glance at the thorax on the screen and on occasions such things may be noted as, secondary carcinoma, pulmonary tuberculosis, abscess collection or cavitation and other pathological conditions of the thorax.

\section{Accessory Equipment}

For convenience in carrying out the opaque enema examination the combined trolley on wheels incorporating an adjustable enema can with cage and glass 'jar container (to hold 4 pints), has been found most convenient. To the glass jar exit opening (situated an inch or more from the base to prevent blockage by any precipitated barium) is attached the rubber tubing, and incorporated at the end a Higginson's syringe with the valves removed. Removal of the valves permits flow both ways and so facilitates testing pressure by hand or clearing tube blockage.

The older variety of rectal nozzles made of bone and metal have now been discarded for radiological work at St. Mark's Hospital. Instead of these the rubber self-retaining catheter-such as the "de Pezza" No. 28 or 30 catheter-is now employed. These catheters are easily sterilised by boiling and simply inserted by aid of a metal stillette. The head of the catheter should be freely lubricated by one of the sterile lubricants now available on the market.

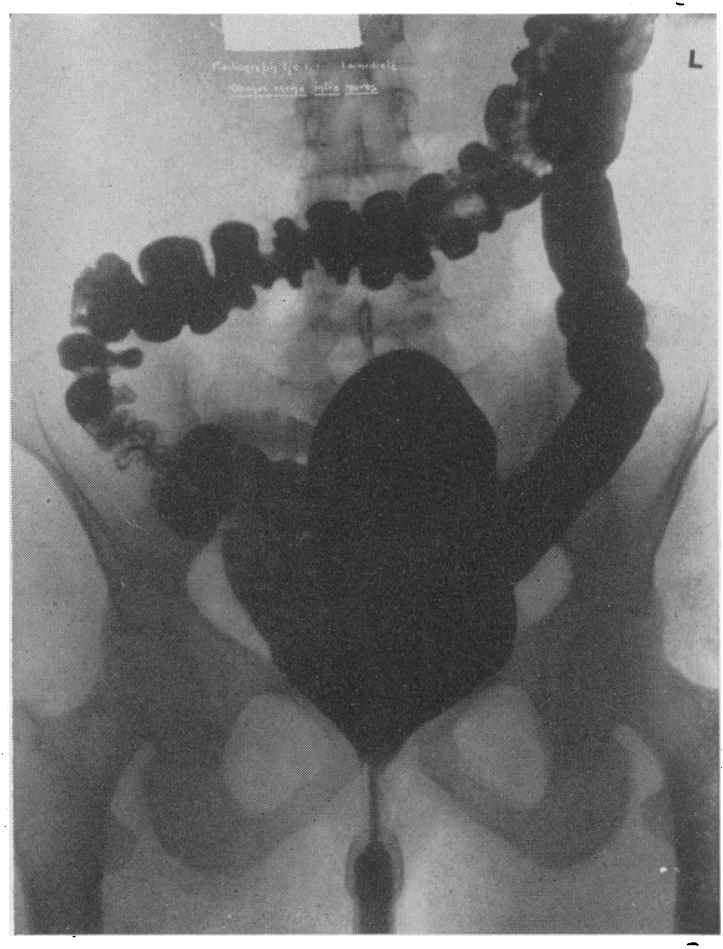

FIG. 3a.-Example of incompletely or carelessly administered opaque enema.

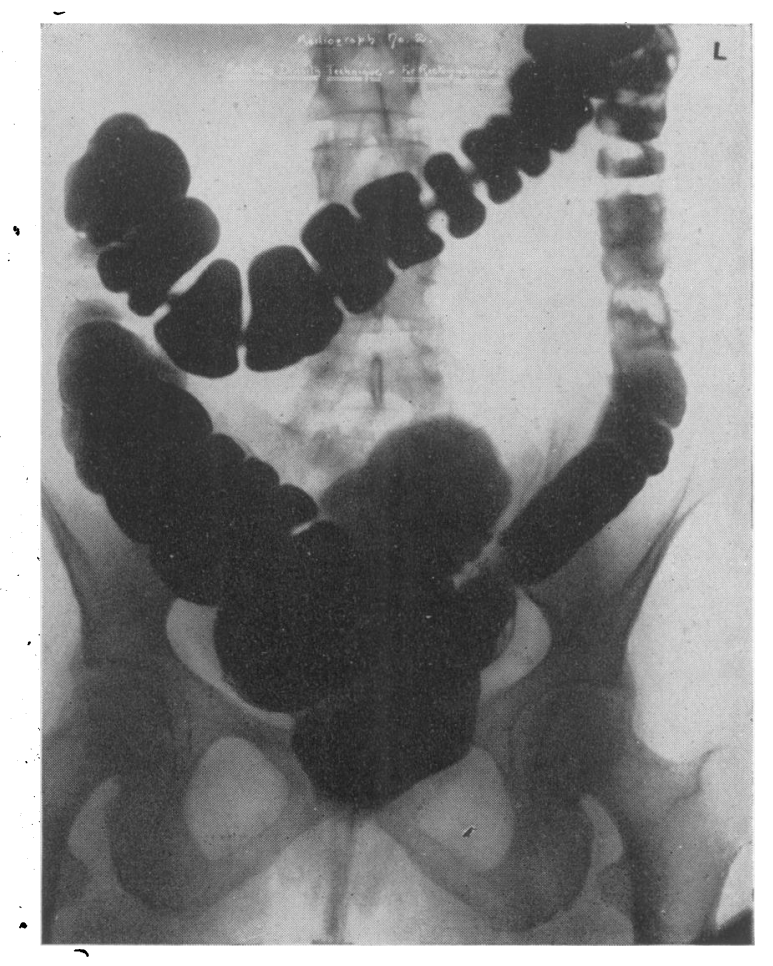

Fig. $3 b$. -The same case with enema correctly administered. 


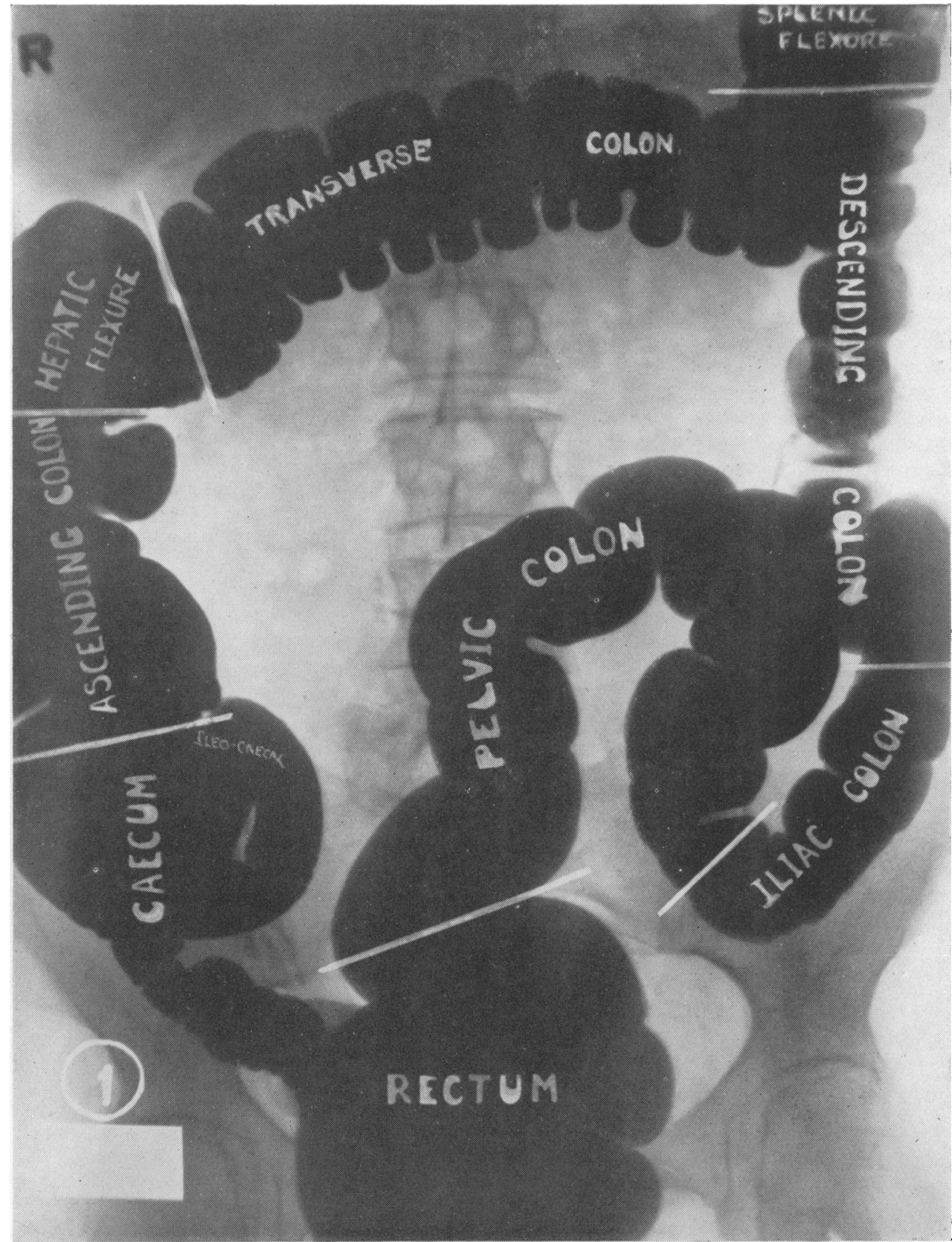

FIg 4.-Anatomical limits. 


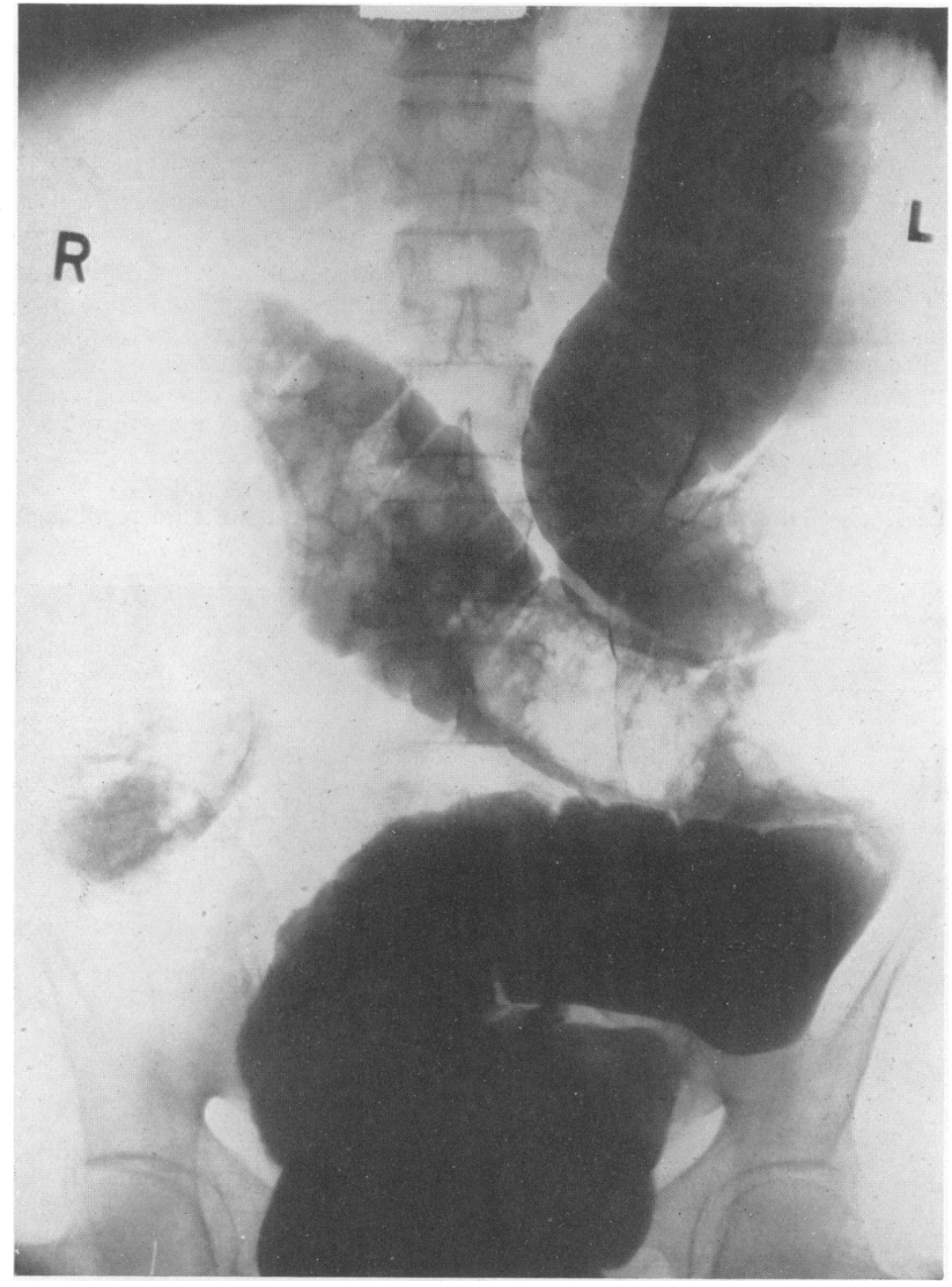

FIG. 5-Megacolon with small carcinoma showing at the recto-sigmoidal junction. 


\section{The Opaque Enema and its Variations}

These may be conveniently grouped as follows:-

I. Standard or "classical" barium enema.

2. The combined opaque enema with or without air inflation and using compression.

3. The combined contrast air inflation enema.

4. The combined opaque enema, using opaque fluids other than barium.

5. Reduction density opaque enema.

Following this classification let us consider each method in turn:-

\section{The Standard or "Classical" Opaque Enema.}

This form of examination still continues to-day the most favoured form of enema to be employed. Using this type of opaque enema to display some minor faults, in Fig. $3 a$ it is seen how it can so easily be incompletely, or perhaps carelessly administered. It is clear in Fig. $3 a$ that the colon has not been properly filled, with the hepatic flexure ptosed,

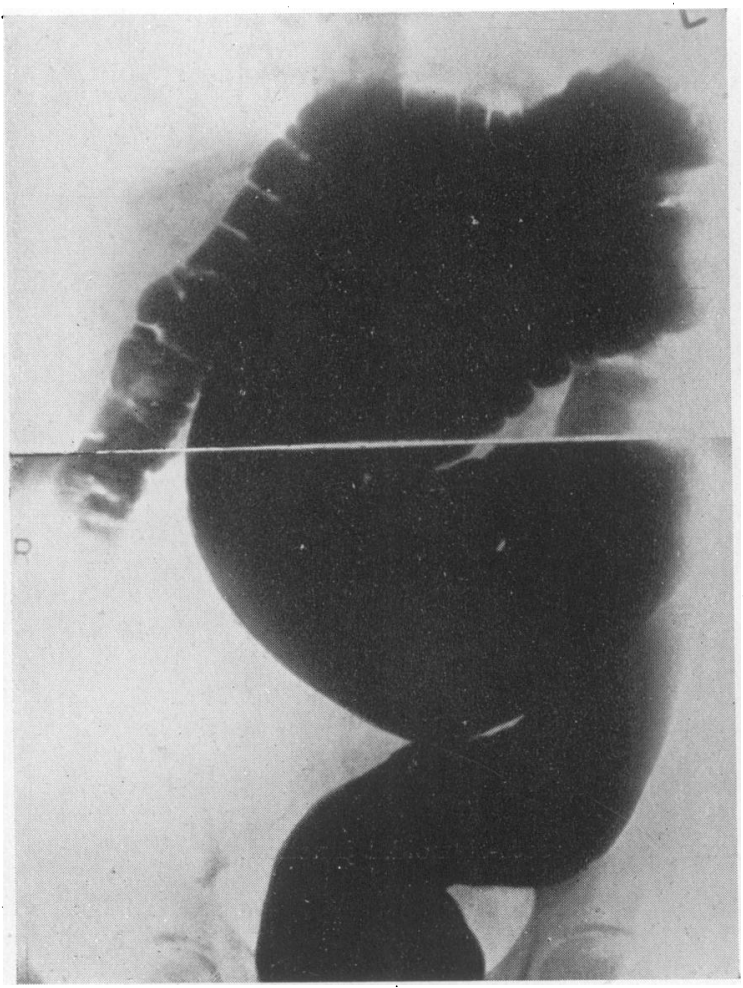

FIG. 6.-Shows the greatly dilated colon from the splenic flexure to the rectum, while the area of the transverse colon seen filled shows normal calibre. the caecum not filled, while the folds of the pelvic colon are not properly differentiated at all, and it is frequently in this area of the colon that the early carcinoma so often hides. Radiograph $3 b$ shows the same case properly filled and demonstrating a normal colon.

\section{The Normal Colon and some of its Variations.}

For the moment let us refresh our memories and look at the normal colon, with its divisions into rectum; pelvic colon; iliac colon; descending colon; splenic flexure; transverse colon; hepatic flexure; ascending colon; caecum and appendix, as diagrammatically shown in Fig. 4.

A fairly common variation from the normal colon is the enlarged or hypotonic variety of bowel, and going one stage further the megacolon. In Fig. 5 we have an example of what at first sight appears a simple case of megacolon with severe constipation. One must however be on guard in these cases because more careful search revealed in this case a small irregularity of the wall contour at the pelvi-rectal junction resulting in the finding of

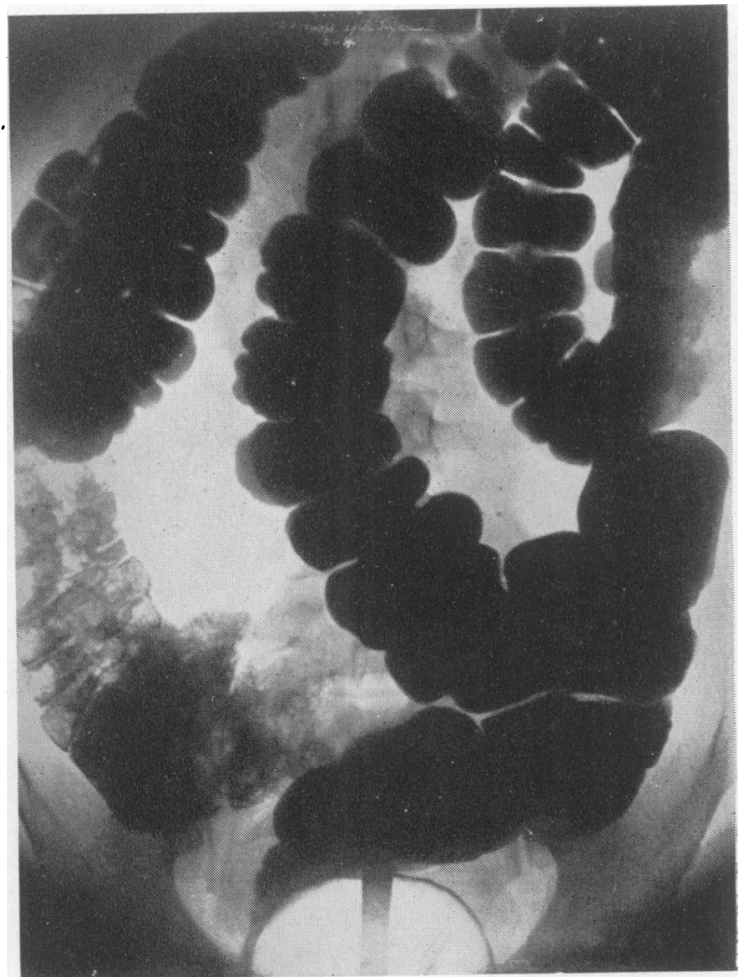

FIG. 7.-Same colon after administration of spinal anaesthesia and St. Mark's anti-incontinence catheter in rectum holding the enema. 
a small carcinoma radiologically, which was subsequently confirmed clinically.

Cases of true megacolon however do occur but are not so very common. The case shown here, Fig. 6, emphasises the greatly dilated bowel from the splenic flexure to the rectum while the area of the transverse colon seen filled, shows normal calibre of bowel. The next radiograph (Fig. 7), taken of the same case some fifteen minutes later, was after the administration of a spinal anaesthetic and the bowel now shows good and practically normal contraction and tone throughout. When, however, the same case was operated upon and sympathectomy performed the expected result to produce an effect similar to that as seen in Fig. 7 was not achieved and so we are forced to the conclusion that in these cases of megacolon with chronic constipation the operation for performing sympathectomy is not infallible. The most severe case of megacolon I have on record required II pints of opaque enema to fill the bowel. In another case of which I only saw the post-mortem examination, the large intestine was so dilated as to almost entirely occupy the abdominal cavity. The patient was reputed to have had only one motion of the bowels in six months and I should imagine if one could have carried out an opaque enema examination it might have resembled the case recorded above that required II pints of barium.

\section{Tumours of the Colon}

Perhaps disease of the rectum is hardly the province of the radiologist, but occasionally one does come across pathology in the rectum, which may have been overlooked by a quick sigmoidoscopy examination by the clinician, or a doubt may have arisen as to the extent of the infiltration of the rectal wall, and particularly if the growth is in the upper part of the rectum.

One such case is recorded here in which the clinician reported a stenosis of the rectum, and referred the patient for an opaque enema examination. This revealed clearly a growth involving the rectum with stenosis. Sometimes the excessive oedema around the stricture opening prevents clinical observation with the sigmoidoscope, and so radiology comes to help in these cases.

An unusual variety of case is recorded in Fig. 8

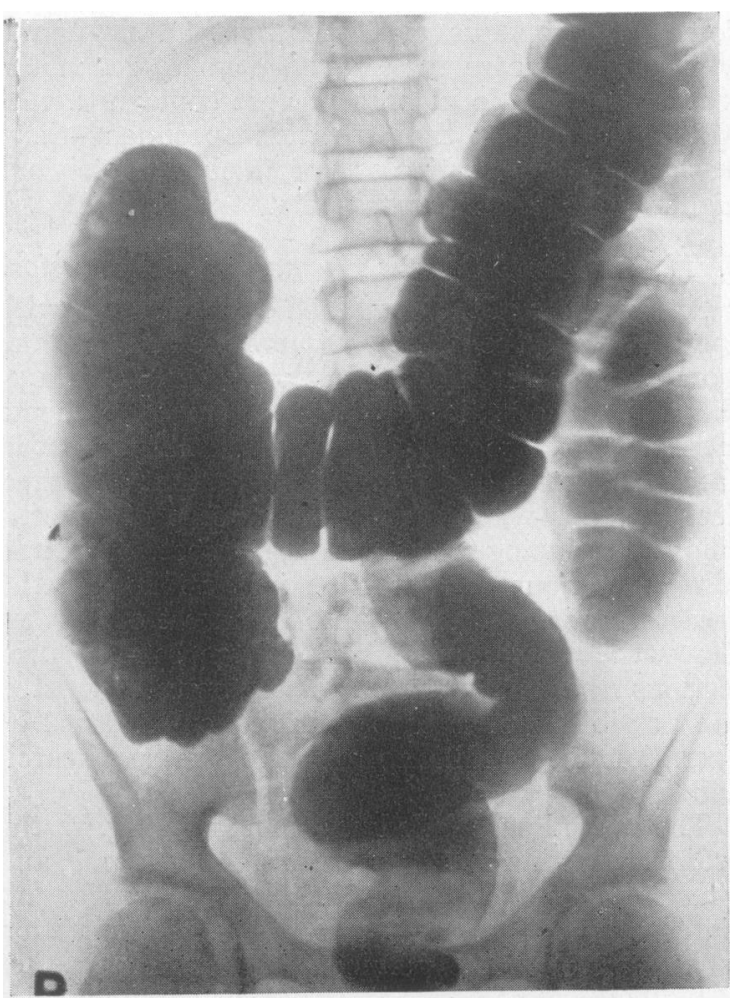

FIG. 8.-Cavernous angioma.

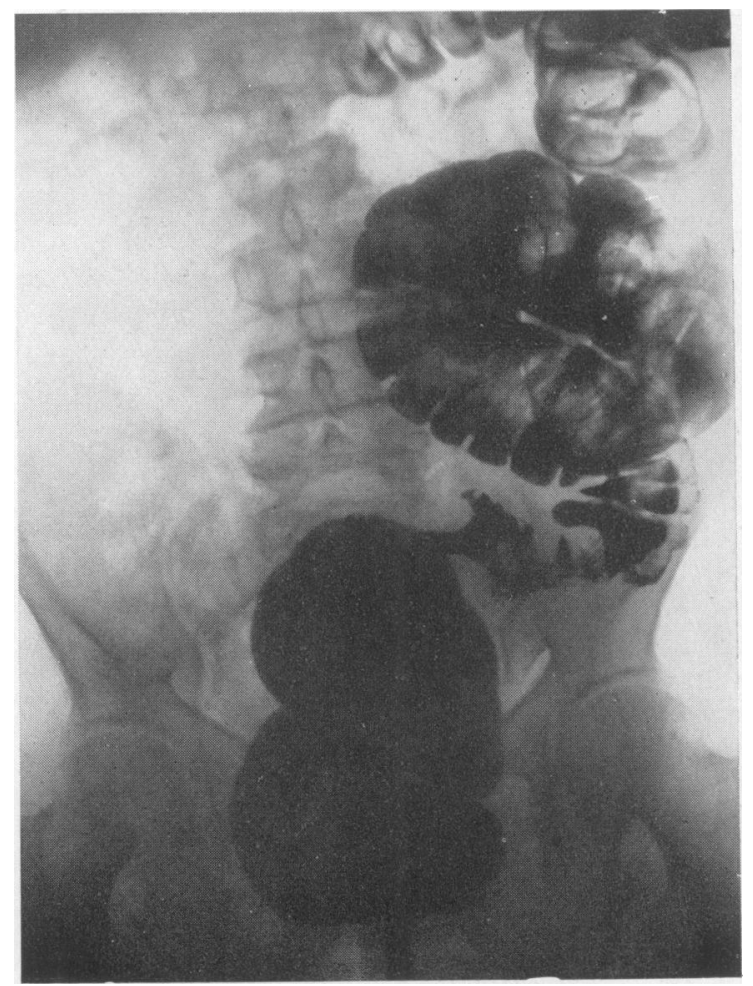

FIG. 9.-Carcinoma of the pelvo-rectal junction with stenosis. 
by "Reduction Density" technique showing a cavernous angioma. The only points to be noted in such a case were the few indentations of the dilated venous vessels around the rectum and adjacent part of the pelvic colon. The air inflation radiograph in this case was of no value as an aid to diagnosis.

As an example of typical annular carcinoma involving the recto-pelvic junction, Fig. 9 is a good example. The growth in this case is producing a great narrowing of the bowel lumen, while pressure of the enema has dilated the rectum, and above the growth the bowel shows an indifferent hypotonic and dilated state with much constipation. The interesting feature in this case was that the patient only complained of chronic constipation, and otherwise appeared to enjoy good health.

In contrast to this case is that of a very early carcinoma revealing itself as a very small filling defect of the right border of the distal part of the pelvic flexure (Fig. I0). In the right oblique view there is just the suggestion of an area of incomplete filling, but just sufficient to warrant the diagnosis
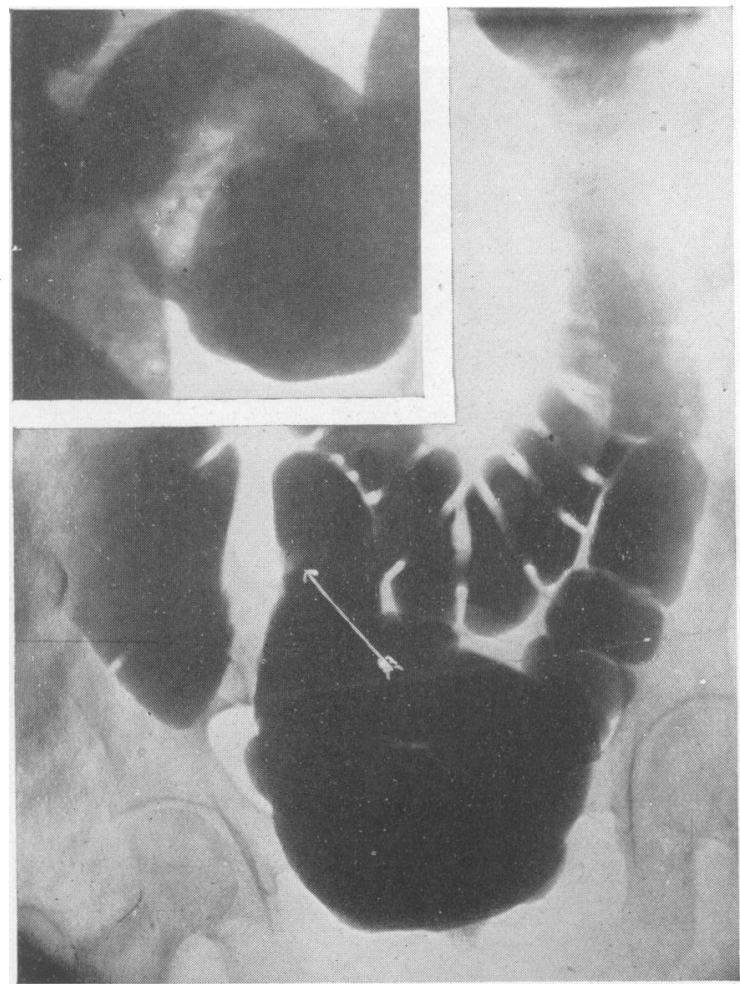

FIG. Io.-Very early carcinoma of the sigmoid flexure showing only groove filling defect along the right side, with insert local of the right oblique view. of early new growth, which at operation proved to represent a small button type of carcinoma slightly over one inch in diameter.

Then there is the type of case that presents in the postero-anterior view what appears to be a typical normal opaque enema (Fig. II $a$ ), but when viewed in the right oblique plane a distinct and sharp narrowing in the ileo-pelvic region is recorded (Fig. II $b$ ). On closer examination the filling of the dilated bowel beyond the stricture shows a local deficiency to penetration, suggesting some thickening, or infiltration at this point, and at operation another small carcinoma was found. Another case almost identical in appearance but with no variation of density signifying wall infiltration was demonstrated to be only true spasm. These two cases are included to emphasise the difficulties of accurate diagnosis, in these early cases, and a warning to demonstrate how the very early growth might be mistaken for so-called spasm of the bowel. Sometimes carcinoma of the bowel, and particularly in the pelvic colon area is masked by the added complication of associated diverticulosis. In the case recorded in Fig. I $2 a, b$ and $c$, the opaque enema could not be passed beyond the recto-pelvic junction and at this level apart from the obstruction there was the suggestion of a small tag-filling defect. An opaque meal was next administered, which in this case took seven days to reach the rectum and the local filling defect confirmed. As will be seen from the operation specimen-there was an area of diverticulosis producing stenosis but? higher above a small carcinoma.

2. The Combined Opaque Enema with Compression.

As examples of the combined opaque enema with compression, the following two examples are worthy of consideration. In the first case (Fig. I3), the immediate radiograph with the opaque enema intra muros there was a small local filling defect in the iliac colon and the question that required decision, was whether this was a case of diverticulosis producing a small filling defect, or a true case of tumour. Compression was applied to the area under investigation and the insert of Fig. I3 shows the appearance. These large sac-like projections from the lower side of the bowel suggested the possibility of a chronic diverticulosis, but at operation the condition proved to be one of carcinoma.

The second case failed to show anything by the ordinary routine opaque enema, and Fig. I $4 a, b$, and $c$ records the appearance of the antero-posterior and right oblique views. When, however, compression is applied over the pelvic colon a carcinoma of fairly large dimensions is revealed. The explanation appears to be that the large intestine, and particularly the pelvic colon has a high degree of 


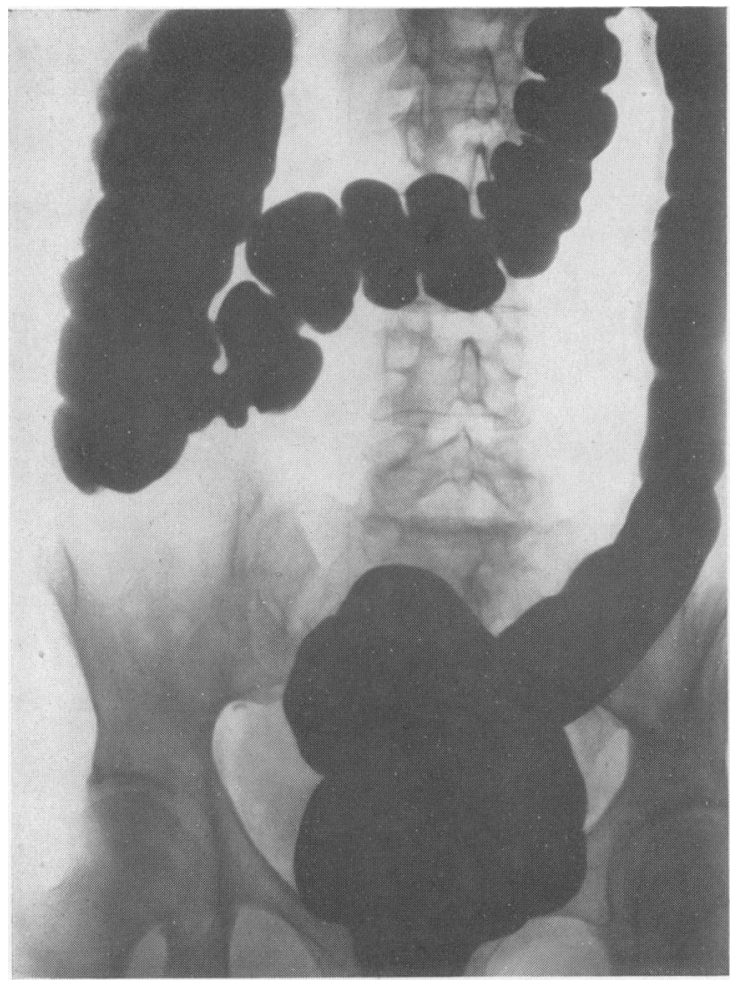

FIG. I I a.-Apparently normal barium enema.

elasticity and contractibility, as is evident in the "dolichocolon" type of bowel, where a pelvic loop may expand and pass right into the upper limits of the left hyperchondriac fossa with the enema under pressure, but when the enema is evacuated the same bowel may contract down into the pelvic cavity until it can hardly be seen. In the case where compression is applied the pressure forces the elastic walled colon on either side of the growth away from the tumour, but the latter being more or less rigid, remains and is revealed.

As an example of the great elasticity of the bowel and its masking effect is the next case (referred to earlier in the introductory remarks), (Fig. I5), and it will be noted how the rectum passes straight into the pelvic colon and proceeds right off the radiograph, passing to the upper part of the abdomen. When the colon was evacuated, this pelvic colon contracted down towards the pelvic cavity, but in the process of this movement two growths were carried up with the expanding bowel and obscured behind its walls. No less than three separate opaque enemata were carried out in search of more definite evidence of two new growths that were found at operation.

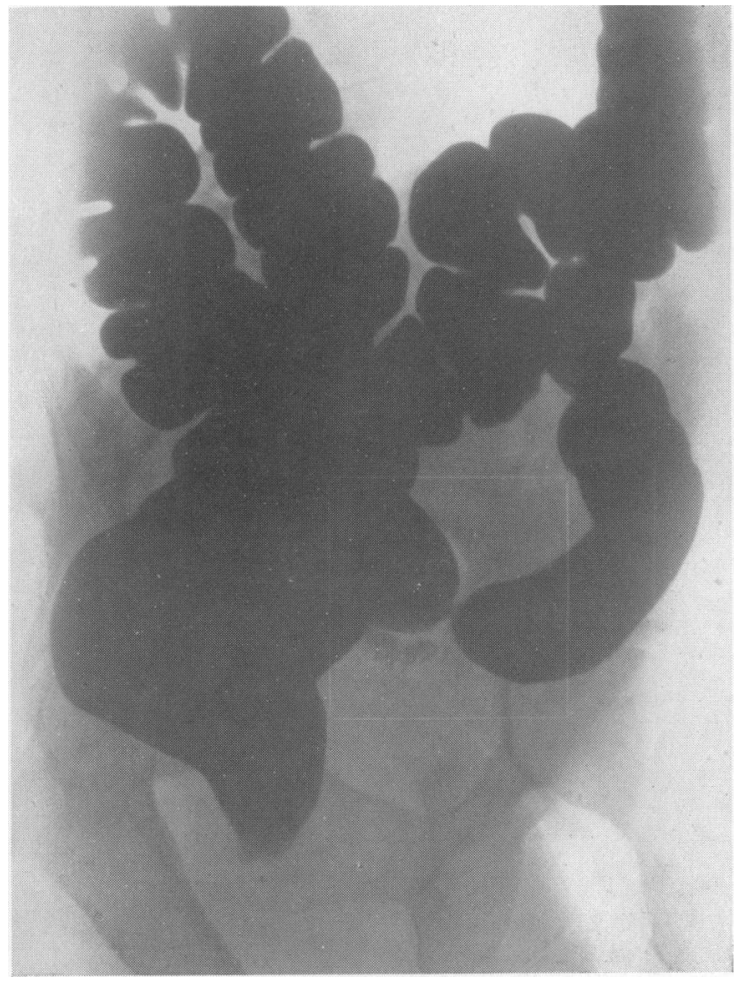

FIG. I I b.-Oblique view showing stenosed area.

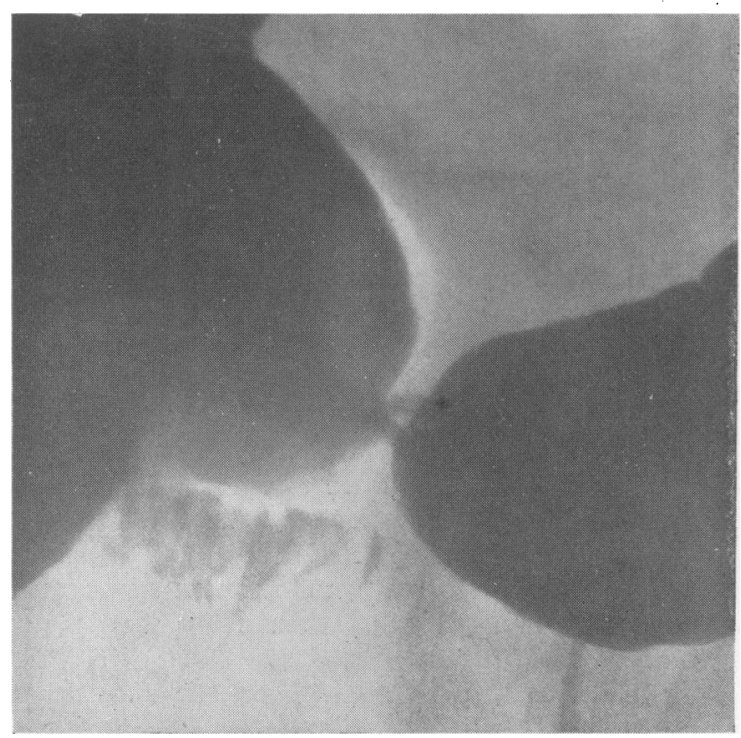

FIG. IIc.-Contact view of the stenosed area showing thickening which at operation proved to be a carcinoma. 


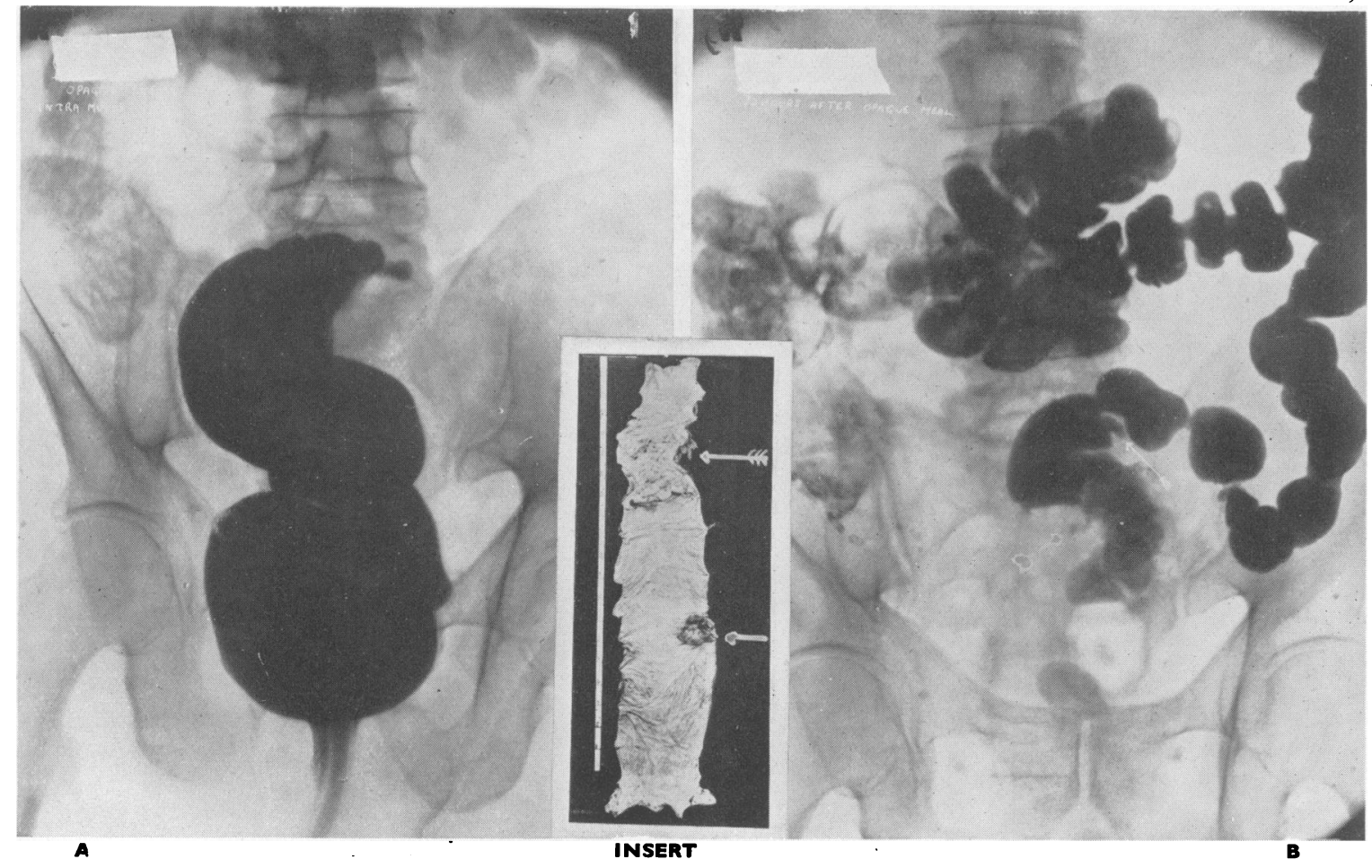

Fig. I 2a.-Opaque enema. b.-Opaque meal. Final stage fibrosing diverticulitis with stenosis and stricture.

Insert.-Post-Operative specimen showing a fibrosing stricture and below, an early carcinoma.

As to errors of technique the following case shows a bowel greatly overfilled with opaque medium, and the result as in Fig. I6. The subsequent examination (Fig. I7), shows the same case with the enema correctly administered, and at the second examination note how a large carcinoma is clearly demonstrated involving the Hepatic Flexure, but masked when the bowel is over filled.

As to other tumours met with in the colon, apart from carcinoma there is the large polypus and as will be seen in Fig. I $8 a$ and $b$, this small tumour produces a filling defect of varying density and indefinite margins. Once seen this type of filling defect is not usually mistaken for that of a carcinoma.

A somewhat similar type of filling defect, however, is produced by a lipoma in the bowel, and an example of this is seen in Fig. I9.

To conclude this group, mention must be made of the tumour-like mass formed by the typical example of an intussusception. During a period of sixteen years I have only been able to record three such cases. These show a local enlargement of the colon partly gas-filled, while in certain examples of intussusception the double channel of barium flowing through the mass has been recorded.
This clearly shows that the channel is not completely blocked as some surgical text-books would lead us to believe (Fig. 20).

\section{The Combined Contrast Air Inflation Enema.}

This technique entails the distension of the bowel with air after the patient has evacuated the original ordinary enema. The simplest method of carrying out this procedure is to use an ordinary bag and bellows, commonly employed for use with the cautery. Special pumping apparatus, as employed on the Continent, is quite unnecessary, but if it is desired the air first can be warmed and filtered through cotton wool or "washed" by passing it through a "Wolff" bottle containing some warmed antiseptic solution before directing it into the colon. This form of examination has proved valuable in the diagnosis of multiple diverticulosis, but I have no hesitation in saying that it is of little value in the diagnosis of tumours of the colon, and in fact can be misleading.

Numerous cases where the ordinary opaque enema revealed little or no evidence of diverticulosis can be shown, but after inflating the bowel with air evidence of diverticula come to light, previously 

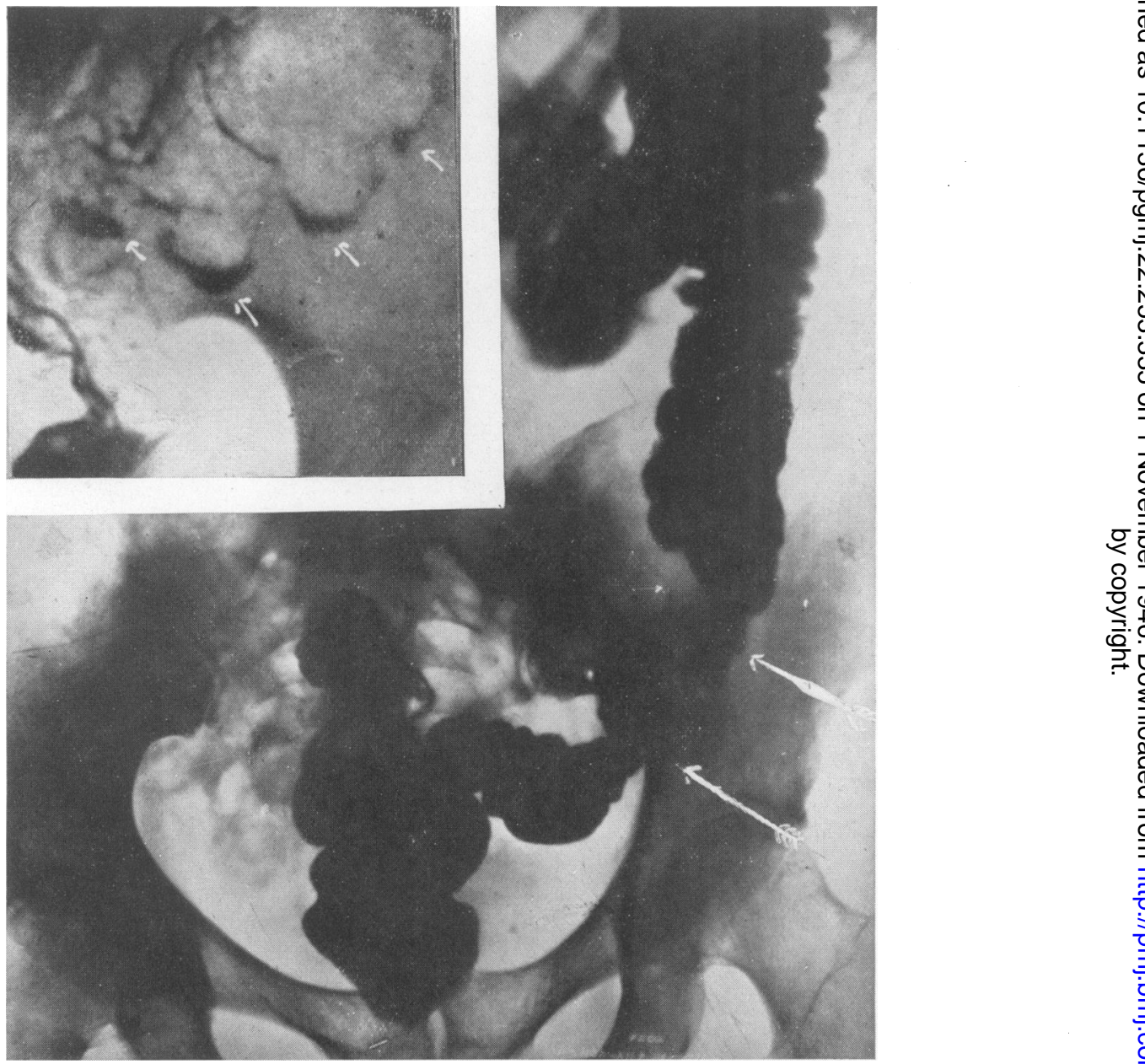

FIG. 13.-Filling defect of iliac colon and insert after compression. The appearance suggested diverticulosis but at operation proved to be malignant. 

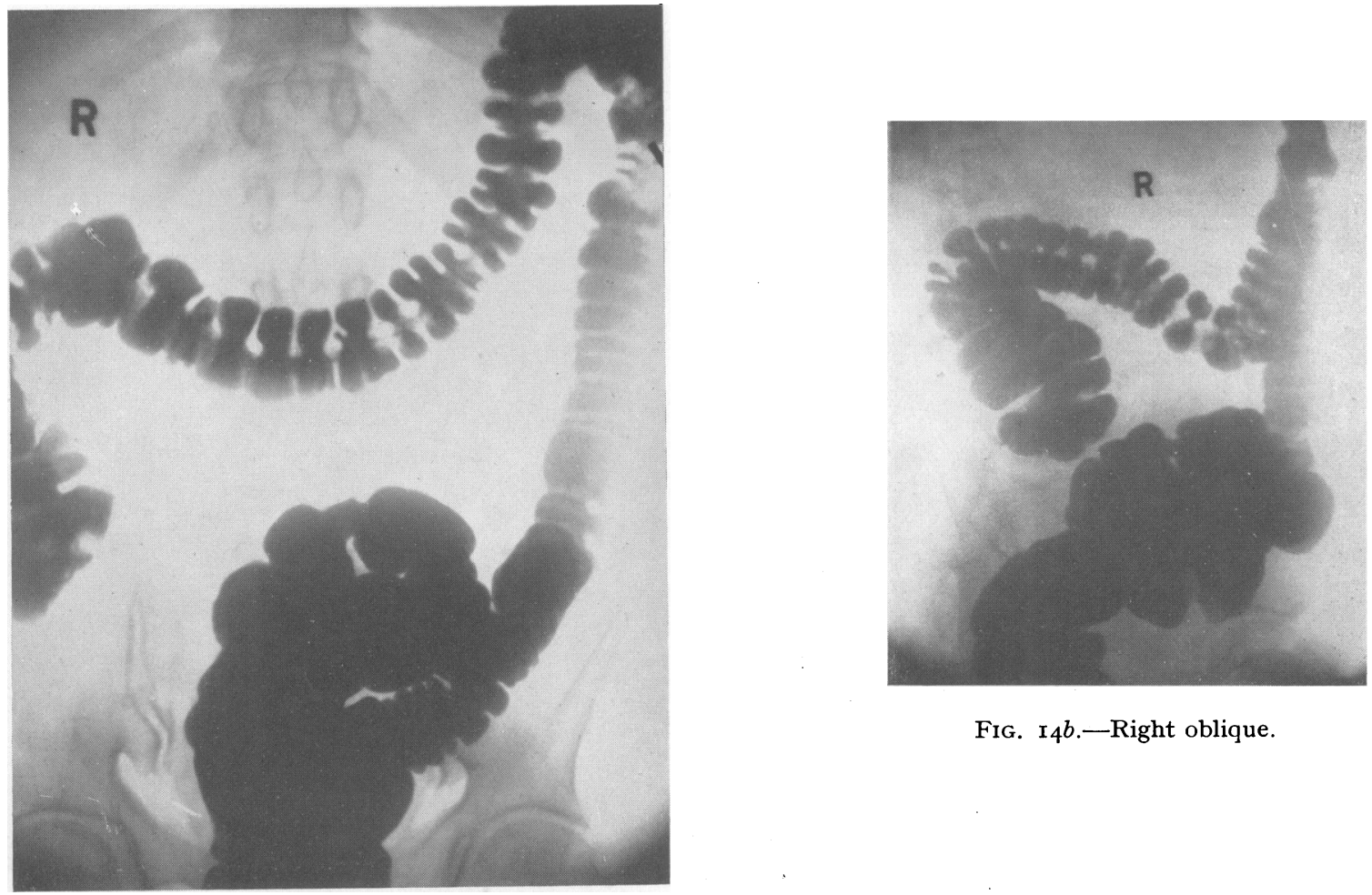

FIG. I4a.-Opaque enema intra muros, showing no Fig. I4b.-Right oblique.

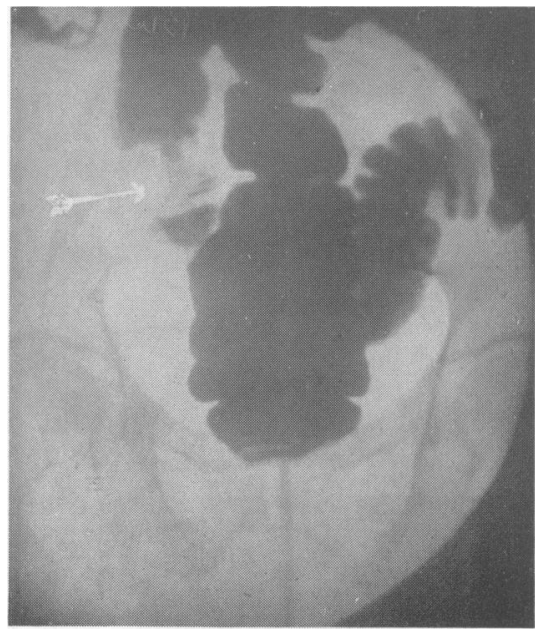

FIG. 14c.-Compression view showing carcinoma. 


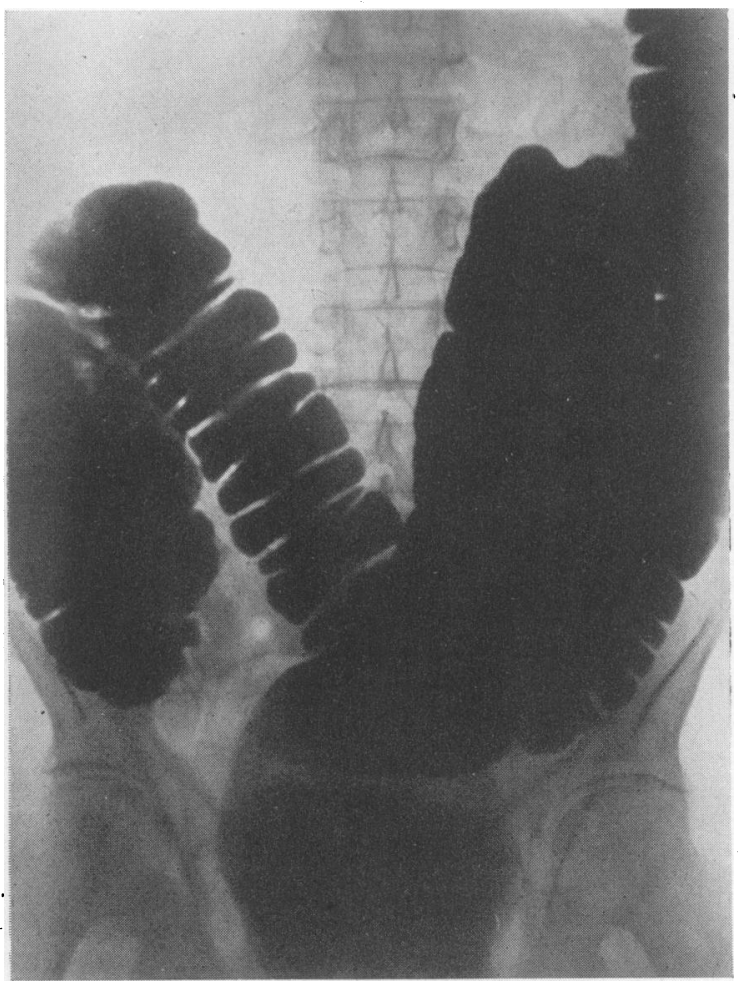

FIG. 15.-Double carcinoma of colon not shown by opaque enema.

unsuspected, and in a few cases numerous diverticula scattered throughout the whole length of the colon sometimes appear. Examples of these will be found under the special section dealing with Diverticulosis and Diverticulitis.

\section{Spontaneous Local Air Inflation of the Colon}

Wherever there is local pathology in the colon it is not an uncommon feature to find during the barium enema administration a small collection, or collections of spontaneous gas production, usually more or less in the immediate vicinity of the pathological focus. The explanation would appear to be that the excess of local bowel secretion in the area, altered or otherwise from the normal state as the result of the pathological lesion present, produces a chemical action with the strong alkaline barium solution. As a result gas production takes place locally and on a number of occasions this spontaneous gas production has directed more attention to the particular area, resulting eventually in most cases of discovering early evidence of disease. The following case is a typical example. Originally an opaque meal was carried out by an independent party and as the result of spasm of the splenic portion of the transverse colon a tentative diagnosis of tumour of this area had been made (Fig 2I). Carrying out an opaque enema at St. Mark's Hospital, we found that the area perviously showing spasm was now well filled, but in the vicinity of the splenic flexure spontaneous gas production had taken place and through the area so shown in relief there appeared what seemed to represent a small and early new growth (Fig. 22). The subsequent evacuation radiograph (Fig. 23), outlines the small tumour even more clearly, and finally the photograph (Fig. 24) shows the small button type of carcinoma that was excised. In this case it should be noted, how again the opaque enema was the method of examination that determined the diagnosis, when the opaque meal apparently failed. In concluding this section I would add yet another case showing the examination by the opaque meal entirely failed to show an early carcinoma on the postero-lateral aspect of the caecum while the opaque enema showed the tumour distinctly. The explanation is simply that with the opaque meal the bowel is not subject to full distension as in the case of the opaque enema. These examples do tend to lend support to the opaque enema as the method of choice when lesions of the colon are being investigated.

\section{Extra-colonic lesions.}

When examining a colon one has to keep in mind the possibility of lesions outside the colon itself and the following few cases are examples more commonly met with. Abscess collection, in or around the caecal area, and most likely originally arising from an infected appendix. These abscess collections occasionally, but rarely come to the notice of the radiologist to-day, and I have record of only one case during recent years requiring an opaque enema to determine its presence.

An ovarian cyst occasionally causes difficulty and usually the patient consults her doctor owing to persistent bowel trouble and if an opaque enema is carried out some local pressure on the colon from without is evident, outlining the smooth contour, in whole or part of the tumour against the background of the compressed colon.

The type of case that sometimes misleads is the patient with an enlarged prostate gland and retention of urine. The overdistended bladder can produce a filling defect of the colon so complete that one might be misguided into making a diagnosis of tumour mass involving the colon (Figs. 25 and 26). On the other hand, if the distended bladder shows pressure over the colon lumen as from without, and with a clinical history suggestive of bladder trouble, it is always wise to suggest that a catheter should be passed and after drawing off 


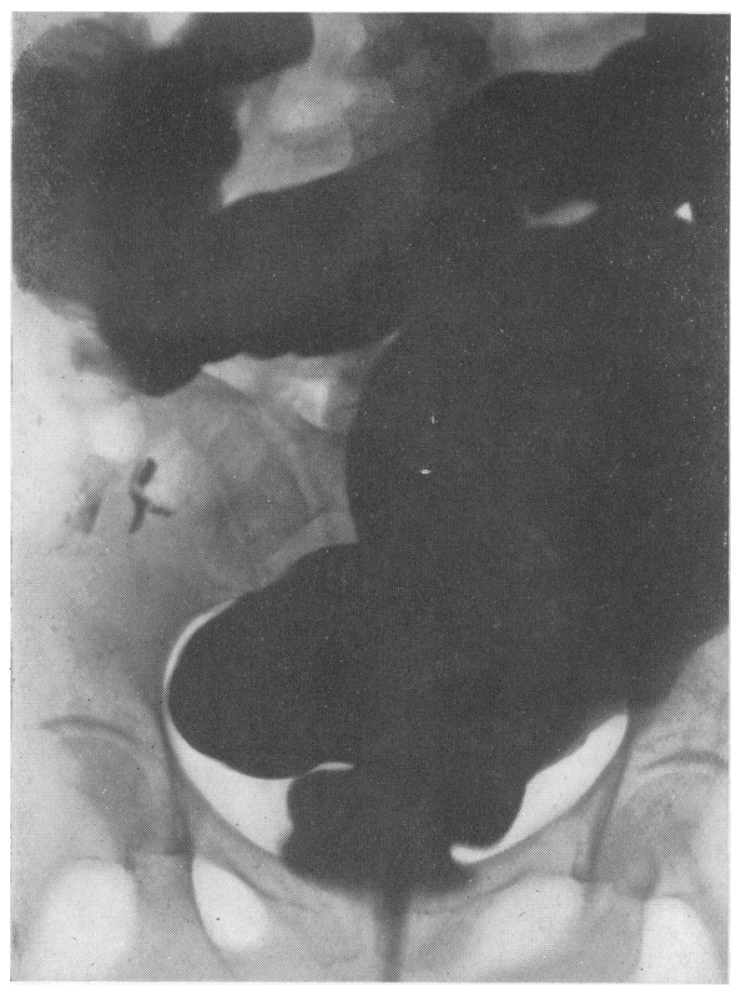

Fig. I6.-Bowel over-filled with the opaque enema masking carcinoma of the Hepatic Flexure.

the urine fill the colon again with barium. In one such case 40 ozs. of urine was removed and the appearance of the filling of the colon was so markedly in contrast that it is difficult to associate the two radiographs with the same patient.

Finally abscesses, such as a ruptured pelvic abscess can produce pressure on the rectum simulating a gynaecological lesion and this possibility should be kept in mind. In one case I examined recently there was marked pressure over the pelvic colon and a radiological diagnosis of tumour outside the bowel was made. Subsequently three surgical opinions decided in favour of carcinoma. The patient's chest was next examined and the radiograph revealed an early local pleural effusion at the right costal angle. Rapidly over the period of the next few months the lungs became infiltrated with what resembled a series of small broncho-pneumonic patches and finally actinomycosis was isolated from the sputum. With massive intravenous doses of Penicillin, the tumour in the pelvic colon disappeared, and gradually the lungs showed resolution, until at the present time they are now almost clear. These extra-colonic lesions are not common but do appear now and again and must be kept in mind.

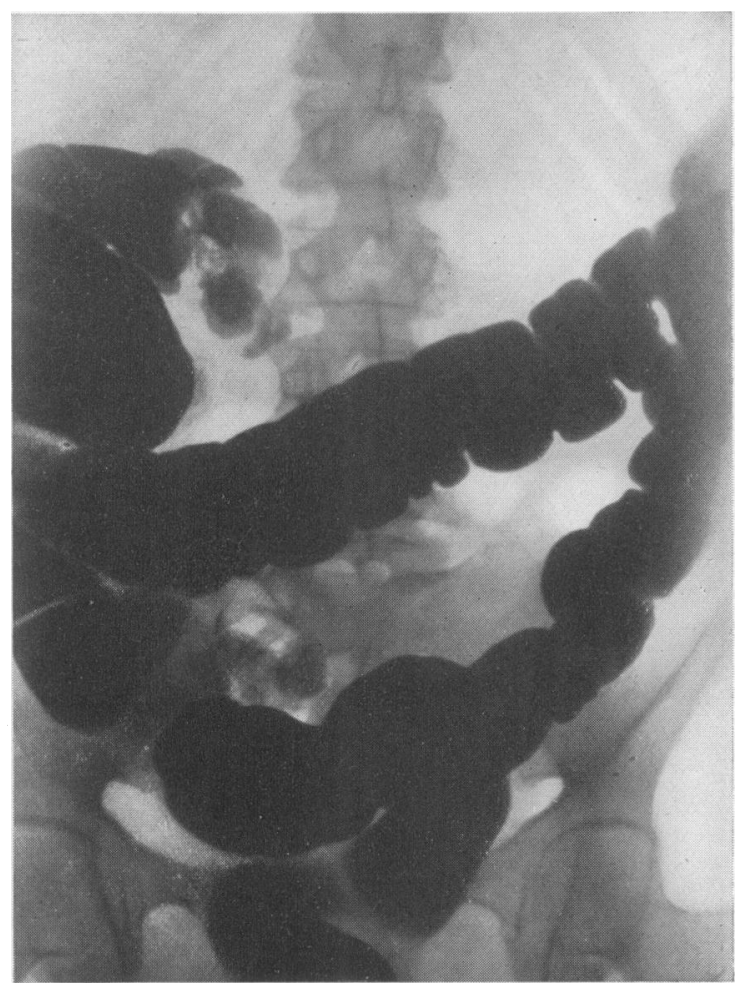

Fig. I7.--Same as 16 properly filled and carcinoma now demonstrated.

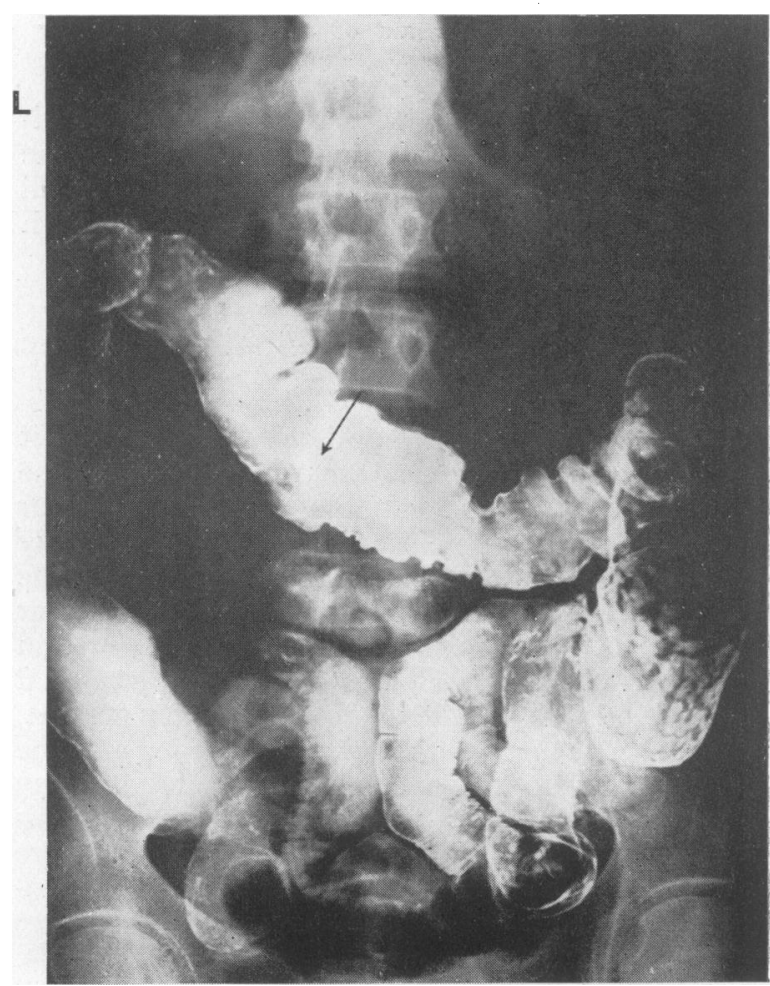

Fig. I8b.-Polyp of transverse colon confirmed at operation. 

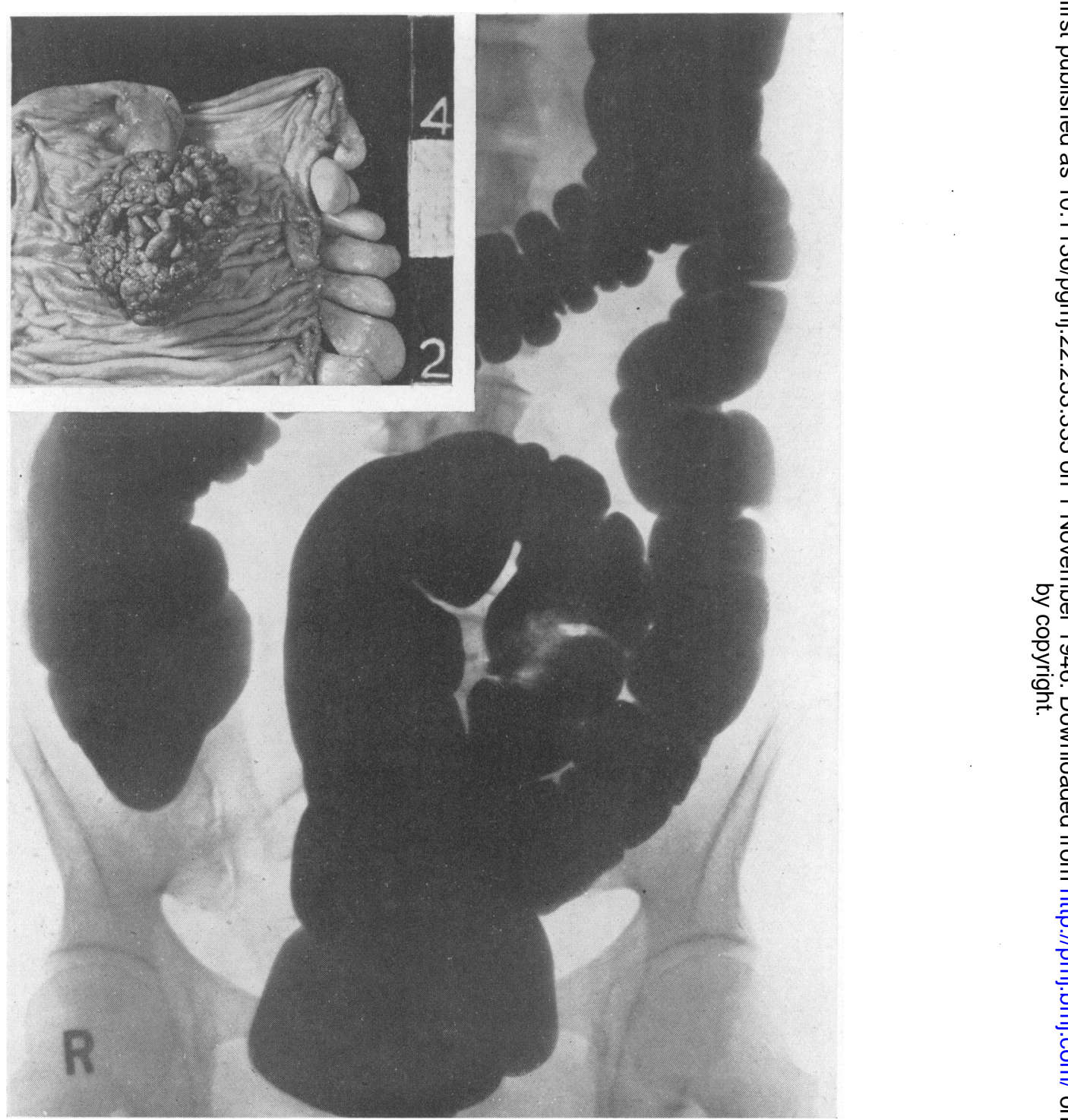

Fig. r 8a.-Filling defect due to polypus and (insert) specimen after operation. 

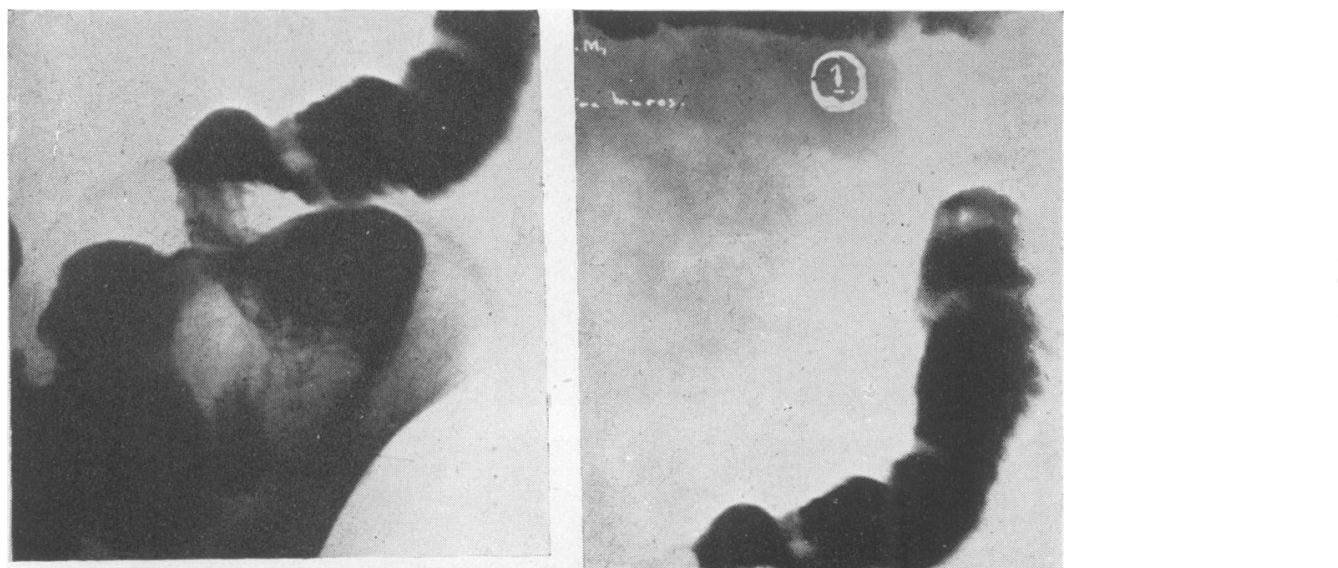

듬

\begin{tabular}{l}
0 \\
\hdashline \\
0 \\
0 \\
0 \\
\hline
\end{tabular}

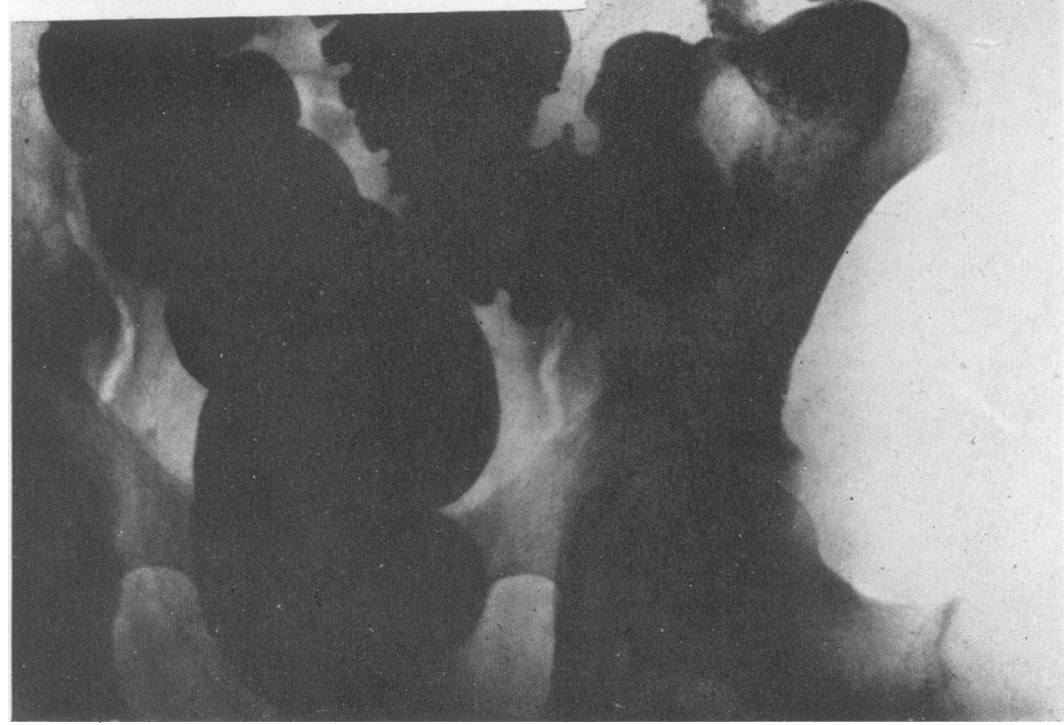

Fig. 19.-Filling defect of lipoma with insert of local area. 


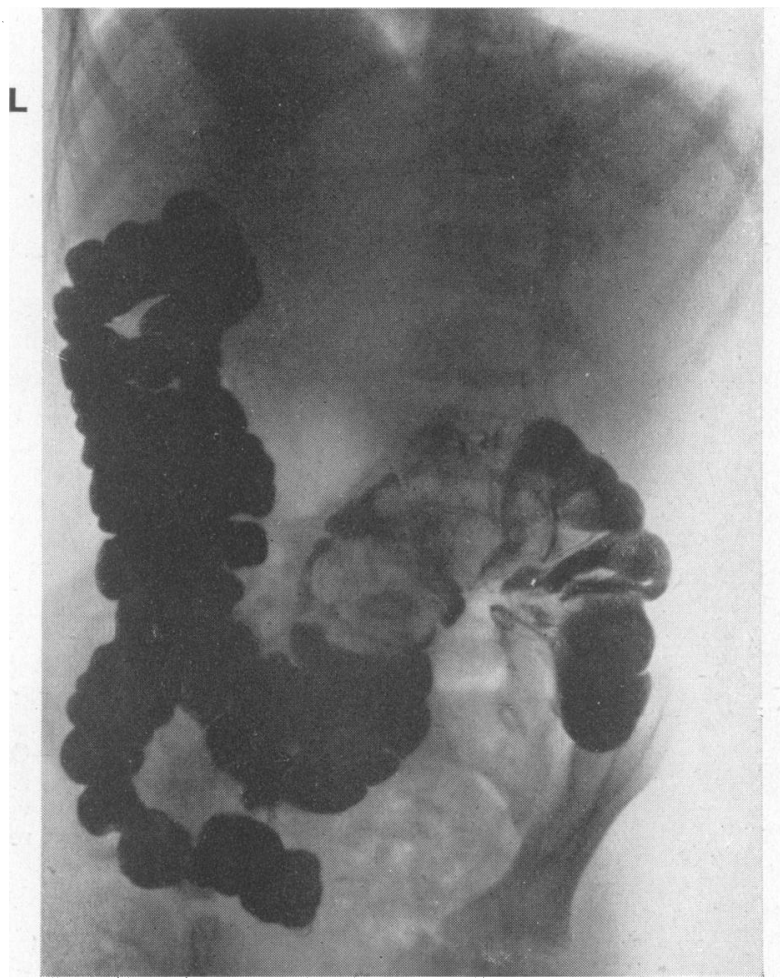

FIG. 20.-Intussusception of the transverse colon.

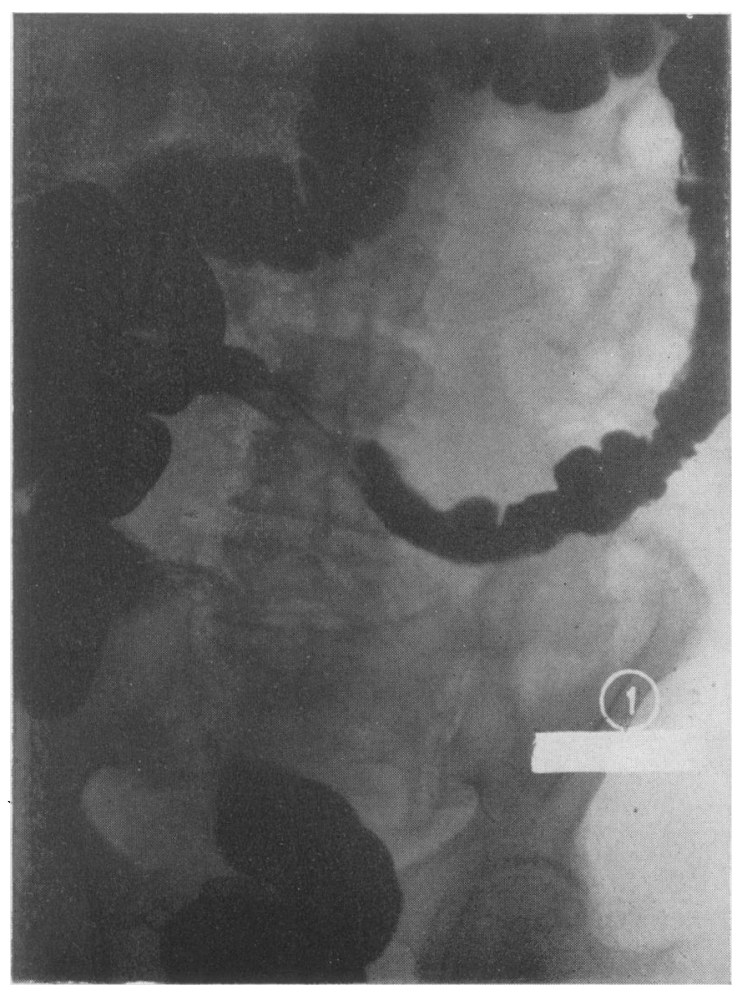

Fig. 25.-Shows first opaque enema.

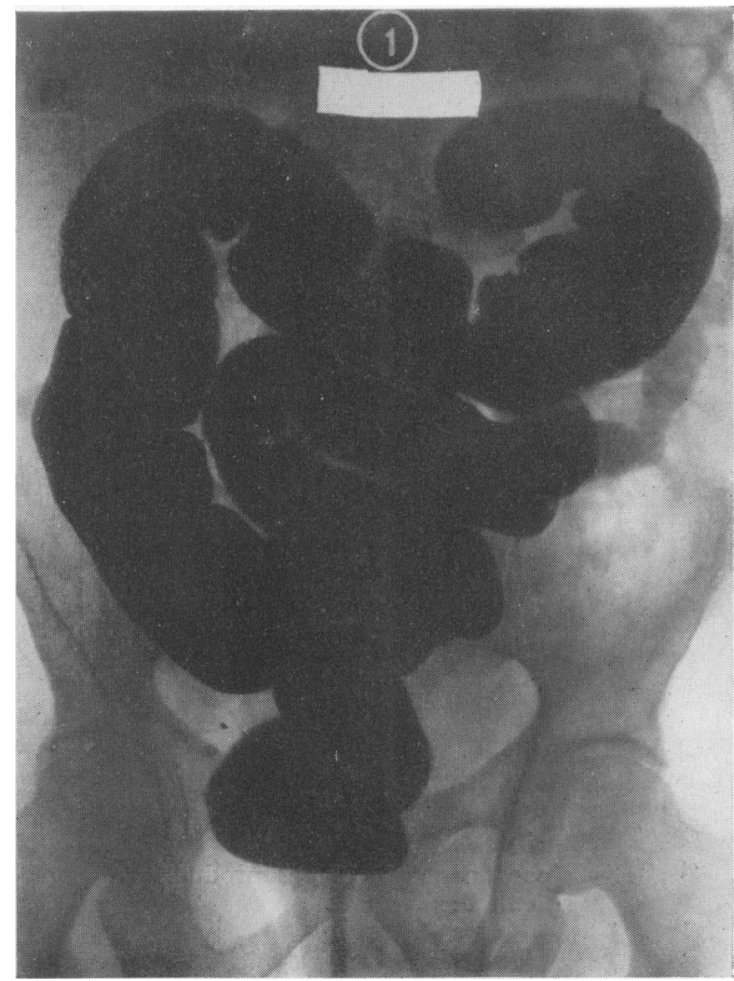

Fig. 26.- Shows second opaque enema after $40 \mathrm{oz}$. of urine have been removed. 


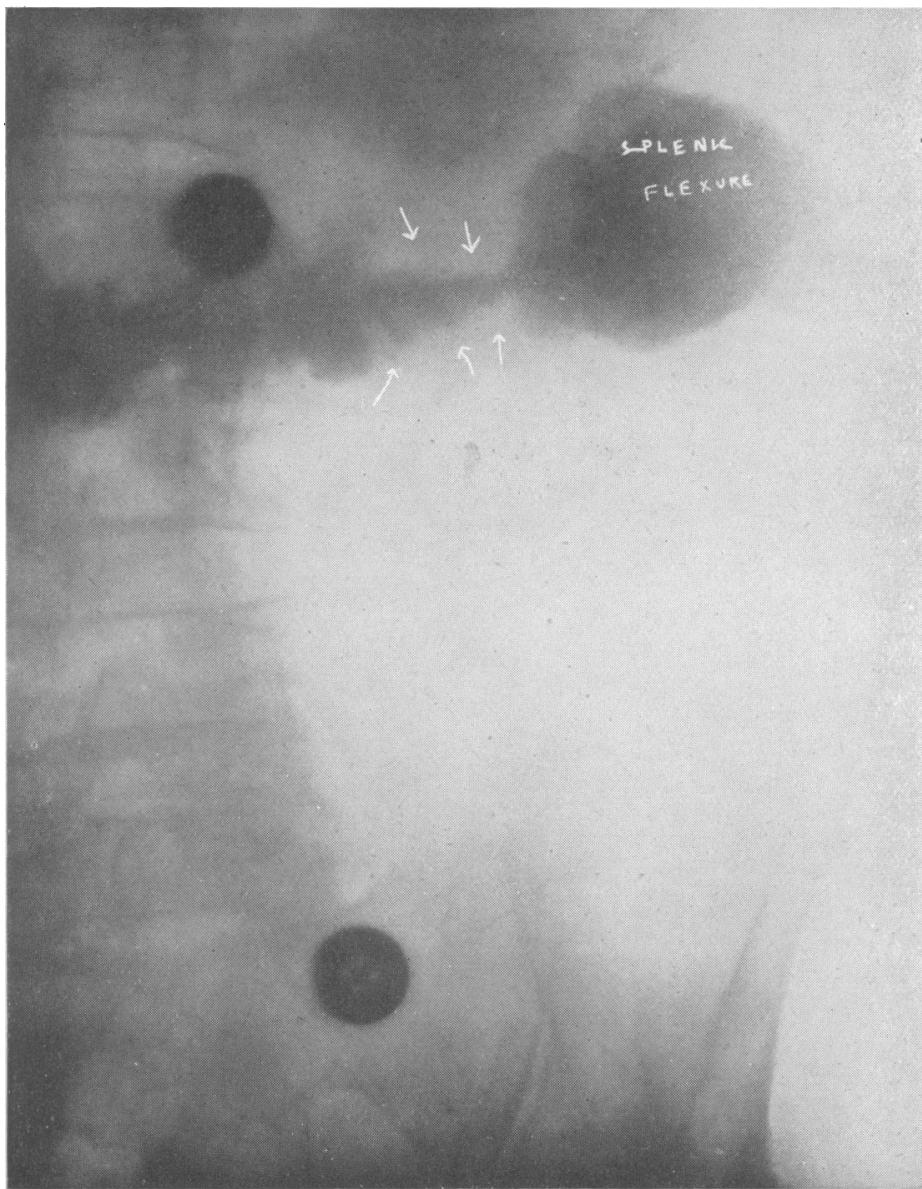

Fig. 21.-Opaque meal radiograph showing spasm of transverse colon and wrongly reported as carcinoma.

FIG. 22.-Spontaneous local gas production splenic flexure area. 


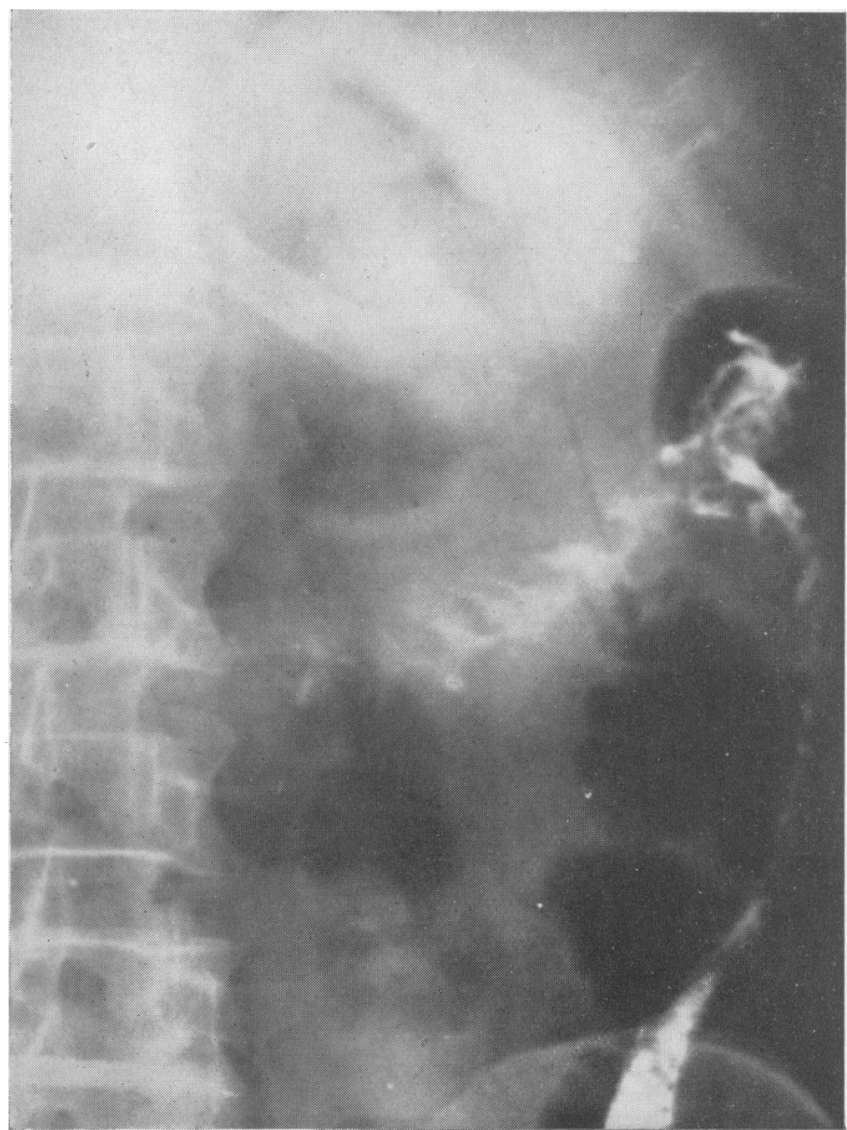

FIG. 23.-Evacuation radiograph. Local gas showing clearly small carcinoma splenic flexure area.

(IFIG. 24.-Excised specimen showing small carcinoma.

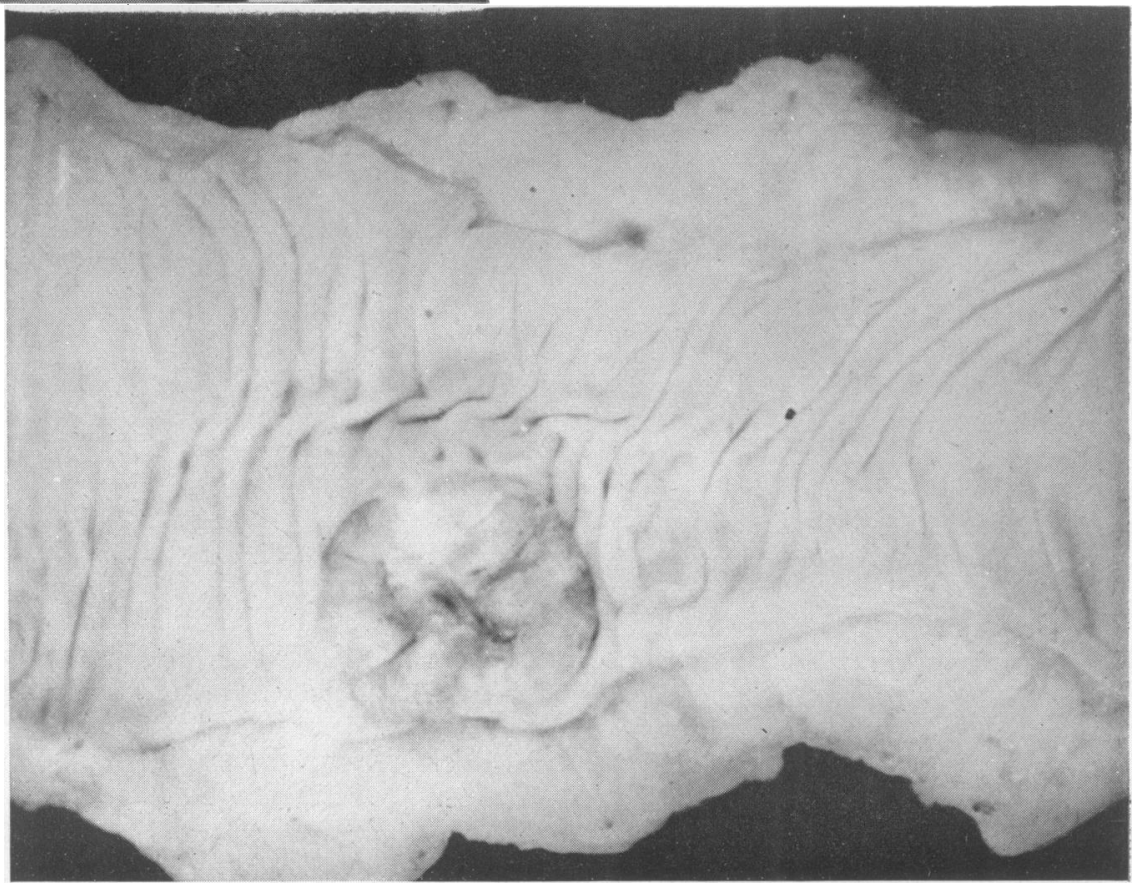




\section{The St. Mark's X-Ray Anti-Incontinence Device}

This device was originally designed in I929 while searching for the best method of carrying out combined air inflation technique, and at that time it was manufactured for me by Messrs. Allen \& Hanburys, Ltd., London, W.I. A full description of the apparatus appeared in the British Medical Journal, I944, March, 4, ii, 328, and also in the British Journal of Radiology, I944, Vol. XVII, I97 and therefore only an abbreviated description will be given here.

The apparatus consisted essentially of a double rubber bag with a catheter (preferably self retaining type such as de Pezza) passing through the channel. With the aid of a proctoscope the complete device (with catheter inserted) is passed into

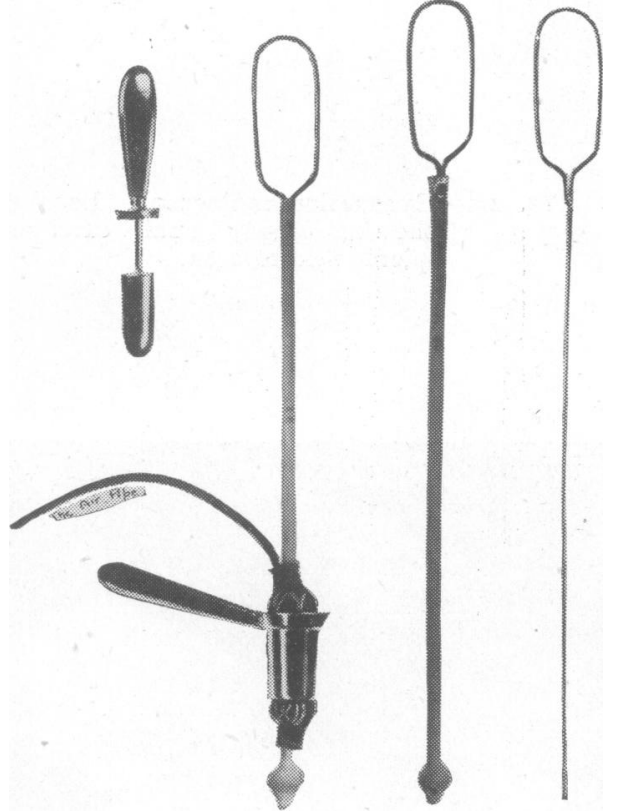

FIG. $27 a$.

the rectum when the "balloon" is distended with air and so secured in the rectum (Fig. 27). The pressure required is only one of $25 \mathrm{~mm}$., mercury, and as the rubber "balloon" acts as an air cushion in the rectum, no damage to the rectal walls is likely, nor has ever occurred in my experience. It will be seen with this "plug" in the rectum, the catheter is held firmly in position, thus permitting the enema to be administered without fear of it being returned or lost by leakage. For cases of badly torn perineum or severe sphincter paralysis, additional pressure is recommended by application of a wad of wool twisted round the catheter and pressed against the perineum, or application of the special accessory compression tray as described in the original article (Fig. 28).

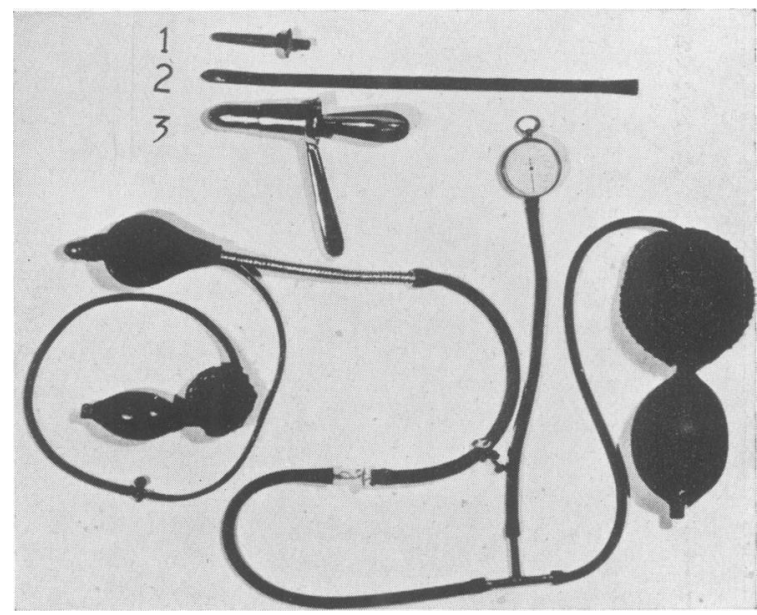

FIG. $27 b$.

A miniature "balloon" measuring one inch in length and taking a child's catheter was designed and used for plugging the external opening of colostomy limb and so facilitating filling of this for washing out purposes or the giving of an opaque enema.

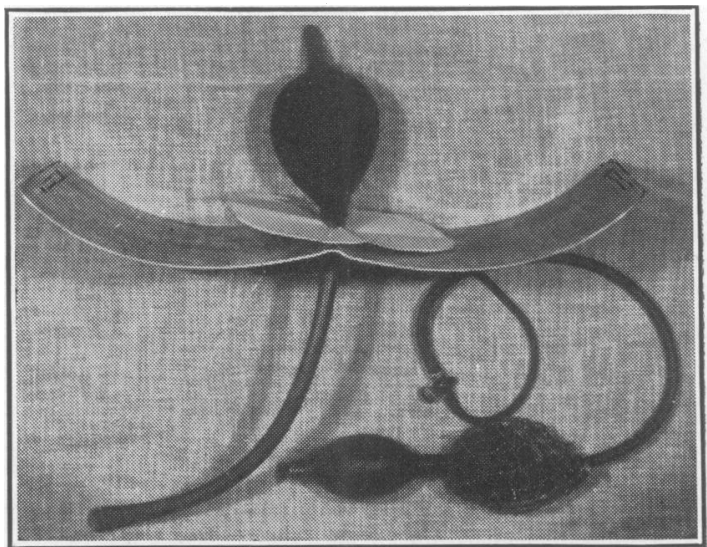

FIG. 28.

As a practicable demonstration of the efficiency of this device the following radiographs of a case of severe incontinence of the bowel are included. The first radiograph (Fig. 29a, $b$ and $c$ ) showed the head of the opaque enema had only reached the sigmoid flexure when the patient became completely in- 
continent. A second attempt after using 6 pints of enema was more successful, but only reached the hepatic flexure when incontinence again set in (Fig. $29 b$.) The third attempt using the St. Mark's AntiIncontinence Device, shows the enema successfully carried to the caecum without one drop leaking back out of the rectum (Fig. 29c).

In this case it is also worthy of note to record how altered the appearance of the pelvic loop appears under pressure, now assuming that elastic expansile appearance of the "Dolichocolon" variety of colon, so commonly associated with constipation, and occasionally carcinoma. solution of barium have appeared from time to time on the Continent and in this country, under various proprietary names such as "Tordiol," "Diagnorthorine," "Collothor," "Umbrathor," and others. Most of these preparations I have tested out, none have proved more successful or efficient than the ordinary standard preparation of barium. Teschendorf (I932) sums up their value as follows: "The value of the method is limited by the fact that relief cannot always be shown," and his observations made in I932 still hold to-day.

Personally I have conducted many experiments with various new and special preparations of the

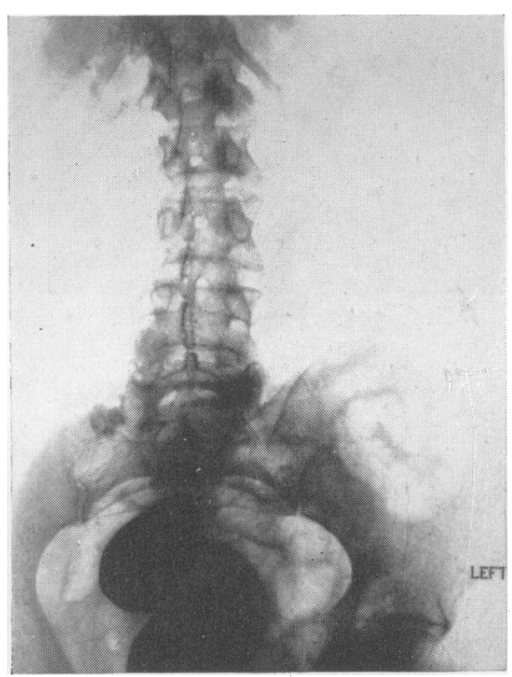

FIG. 29a.-First attempt.

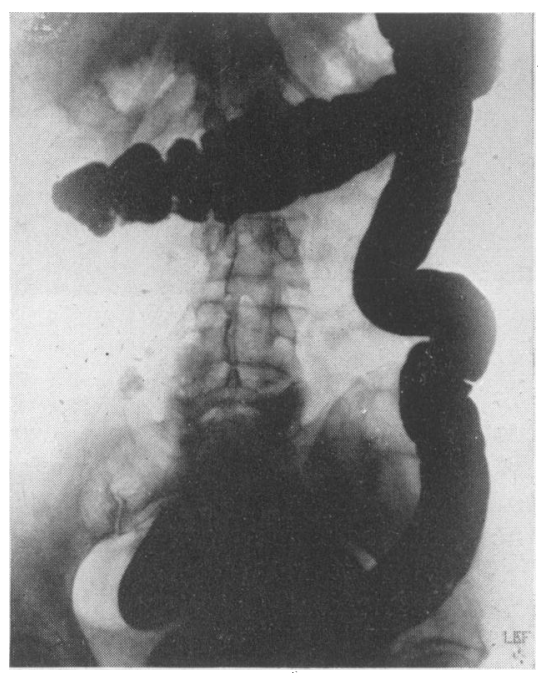

Fig. 29b.-Second attempt.

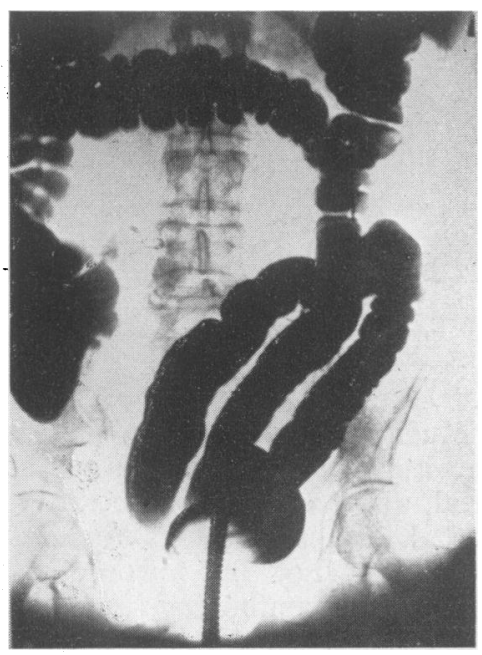

FIG. 29c.-Third attempt, using St. Mark's Anti-Incontinence Device.
This appliance has been in use during the past 16 years with no reported failures in its use, and is recommended to the medical practitioner or exasperated nurse for washing out colons in these difficult cases. The radiologist will find it a great help with the opaque enema and the incontinent patient, or for those cases that cannot retain air when the combined air inflation examination is carried out.

\section{The Combined Opaque Enema Using Opaque Fluids other than Barium.}

A variety of new media to replace the original thorium class, of helium gas and solutions of Iodoxyl in suspension, with in some cases excellent results for opacity to X-rays, but, unfortunately, poor clinging properties to the mucosa. Therc is little doubt that some new solution containing a salt of high atomic weight, non-toxic properties, and capable of adhering to the mucosa might help to give us a more accurate picture of the mucosa pattern than is presently possible with solutions of barium, but much research up to date has so far failed to achieve this result, and for the present we must continue to be satisfied with the results obtained by barium solutions, crude and inefficient as they may sometimes appear to be. 


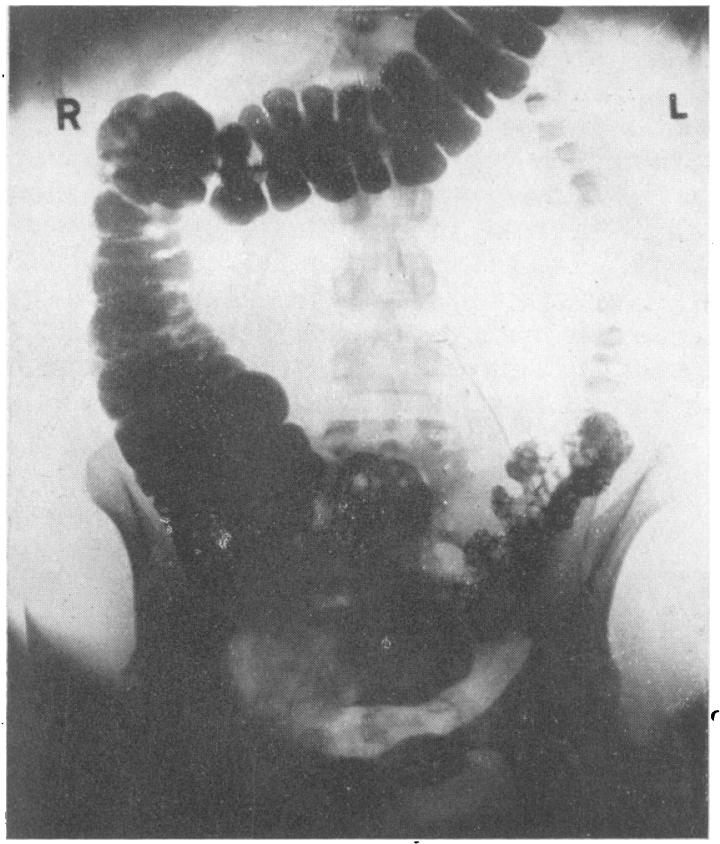

FIG. 30a.

\section{Polyposis Intestini}

Much research work on the subject of Polyposis Intestini has been carried out at St. Mark's Hospital, and the work of Lockhart-Mummery, Cuthbert Dukes and others requires no introduction from me. For the purpose of this review it is proposed to confine my remarks to the radiological aspect only.

Polyposis Intestini is, perhaps, one of the most difficult diseases of the bowel to demonstrate by $\mathrm{X}$-ray examination with any degree of accuracy. Within recent years some Continental workers have claimed that this disease can be demonstrated by the combined air inflation technique. By using this technique the disease can be seen sometimes, but not infrequently air inflation of the colon completely fails to demonstrate these small tumours. I share the view of many other observers, both Continental and in this country, that air inflation technique is of strictly limited value in its application to demonstrate diseases of the colon, and the following radiographs of an advanced case of polyposis intestini support this view.

The first stage of the enema (Fig. 30a) revealed no pathology of the colon at all. Following this by air inflation there was still no trace of the polypi (Fig. 3ob). Yet on viewing the excised specimen (a section shown in Fig. 30c) it was found to abound with many polypi, and I have records of many more similar cases.

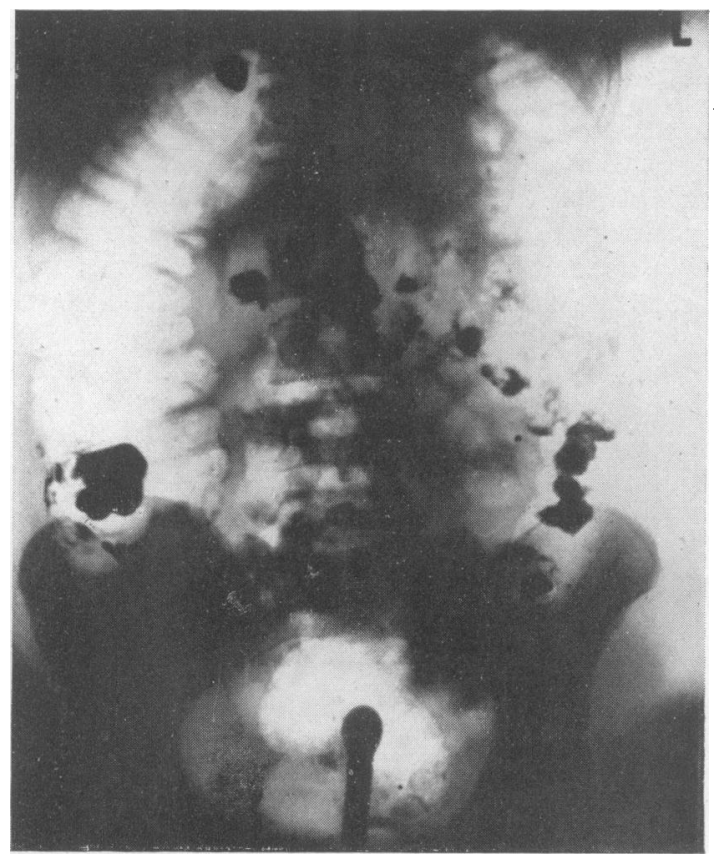

FIG. $30 b$.

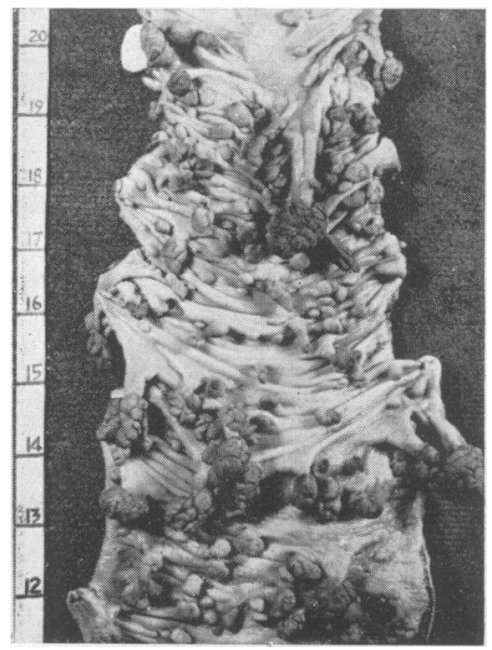

FIG. $30 c$.

FIG 30a.-Evacuation radiograph of a case of polyposis, showing a few polypi in iliac colon area.

FIG. 30b.-Combined air inflation view showing no polypi. FIG. 30c.-Operation specimen showing some of the many polypi found throughout the bowel. 


\section{Reduction Density Opaque Enema.}

As the result of such failures as recorded above the following technique was introduced at St. Mark's Hospital in 1930 and came to be known as "Reduction Density Technique."

An ordinary opaque enema using barium solution in the standard strength is carried out. This is then evacuated by the patient over a period of one to two hours depending on the rate of evacuation until the greater part of the original solution run in has become evacuated. The bowel is then distended by another opaque enema but on this occasion the solution is extremely weak, representing a strength of not more than 3 ozs. of barium solution to the pint of water. The whole procedure is based on the assumption that the original barium

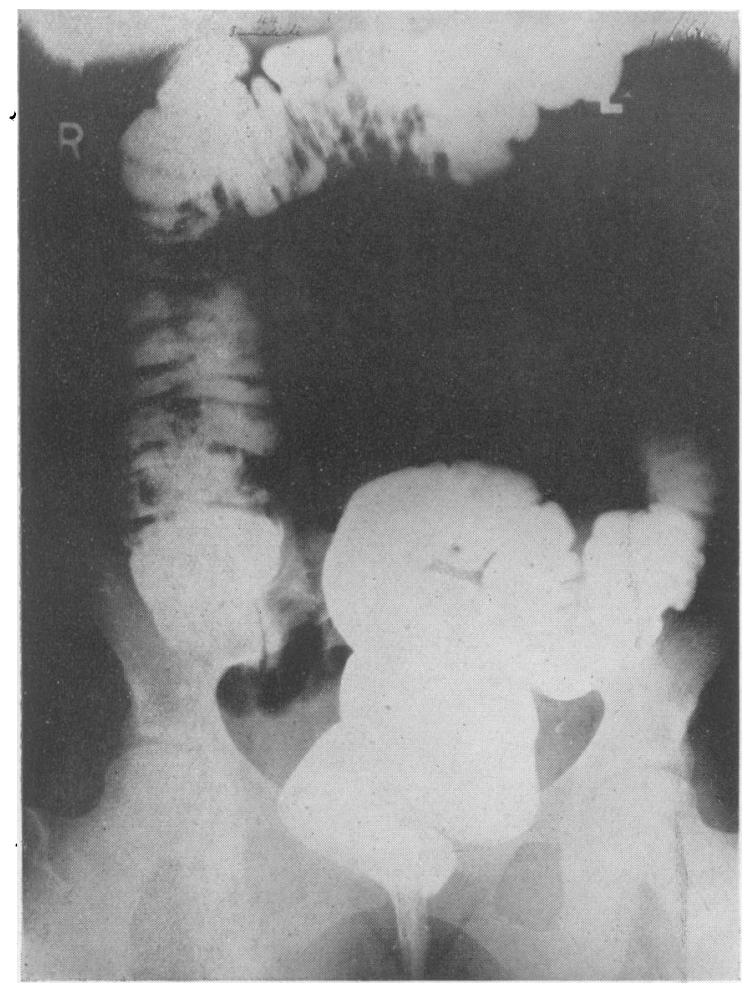

FIG. 3Ia.--Ordinary Opaque Enema. solution tends to cling to pathology in the colon, while the second and weaker solution usually throws this up in relief, and so reveals the pattern of the mucosa. Before the desired effect was achieved with this particular technique many failures were recorded but as will be seen from Fig. 3r $a$, using the ordinary opaque enema, and subsequently Fig. 3I $b$, the result achieved with reduction density reveals a colon studded throughout with multiple polypi that failed to be demonstrated by ordinary methods. A large number of cases examined at St. Mark's Hospital and elsewhere have now been investigated by reduction density technique and one can claim a high proportion of success. The method, however, is not infallible, but is perhaps more dependable than other methods of investigation.

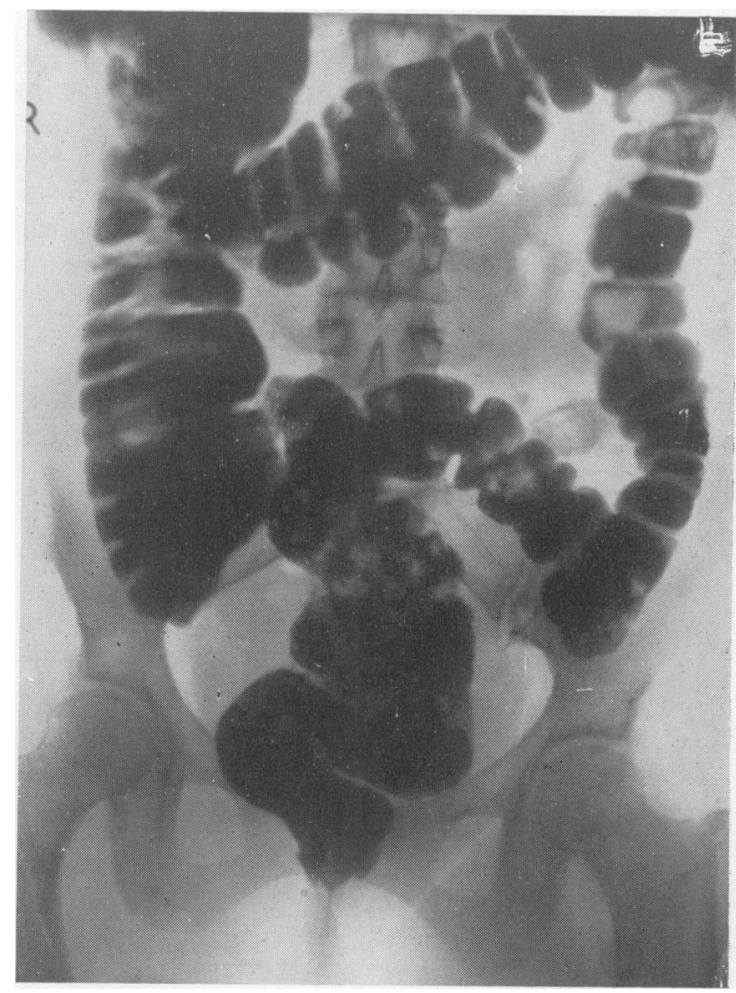

FIG. 3Ib.--Reduction Density technique.

Multiple Polypi shown by Reduction density technique but not demonstrated by the ordinary opaque enema. 


\section{Pneumatoides Cystoides}

To conclude this section of tumours of the colon it would seem fitting to just mention the rare and uncommon condition of gas cysts of the colon. Up to the present time only II cases of this disease (including one of my own recorded this year) are on record in this country. In all, there are just over roo of which details have been published throughout the world. The condition is essentially a collection of small tumours, situated submucosal in the wall of the bowel and the majority contain gas of a composition somewhat similar to that of air. A straight radiograph of the abdomen usually shows these small gas tumours shown up in relief against the darker shadow of the bowel, or even against local gas collections in the bowel itself. They usually appear quite distinct as small translucent circular patches even with the ordinary opaque enema. They are readily mistaken for polypi, but reduction density technique tends to mask the appearance, rather than elucidate the presence of these small gas tumours. In my own particular case all the small cysts instead of containing air, were found to contain fluid and the problem has now arisen as to whether or not these fluid-filled cysts may represent part of the life cycle of Cystoides Pneumatoides, or are we dealing with an entirely new condition. At least I believe this is the first occasion that radiology has successfully demonstrated such cysts in the large intestine, and here I would for the present prefer to leave this subject as their description and question of origin is at this time under review in another paper.

\section{Colitis}

This section of disease of the colon can only be dealt with very briefly in a review of this nature, for indeed this subject could in itself be a matter for a separate paper.

Clinically and radiologically, colitis can be conveniently considered in two big groups:-

I. Acute colitis: For practícal purposes acute colitis may be said to be infective in origin, but on the other hand all infective cases are not necessarily acute. In this stage, however, the radiological picture is common to most of the cases, in that it is a stage of acute irritation, sometimes spasm and hypertonic state of the bowel walls. Discomfort, tenderness or even pain may be a feature, and of course, loose stools and diarrhoea.

2. Chronic colitis: This constitutes by far the largest group, and can be conveniently considered under the following headings:- (a) Mucous colitis.

(b) Membranous colitis.

Follicular ulceration.

Ulceration due to sepsis.

(c) Ulcerative colitis.

Ulceration due to traumatism.

Dysenteric.

Fibrosing (healing stage) and stenosis.

(d) Haemorrhagic colitis.

(e) Colitis of constitutional disease, syphilis and tuberculosis, mucous and membranous colitis are practically the same, both being due to excessive secretion of mucus and radiologically present similar appearances. The appearance in the early stage is that of an irritable bowel, but with a bowel wall somewhat more dilated than in the very acute stage. In fact irritation within a colon beginning to show signs of fatigue of the bowel wall. The appearance is sometimes regarded rather more as a sub-acute stage, while the ulcerative colitis represents the truer appearance of the last or chronic phase. The socalled "string effect" as recorded by some observers in cases of colitis is of little value as a diagnostic feature. In fact this appearance can be produced on occasion following the taking of an aperient.

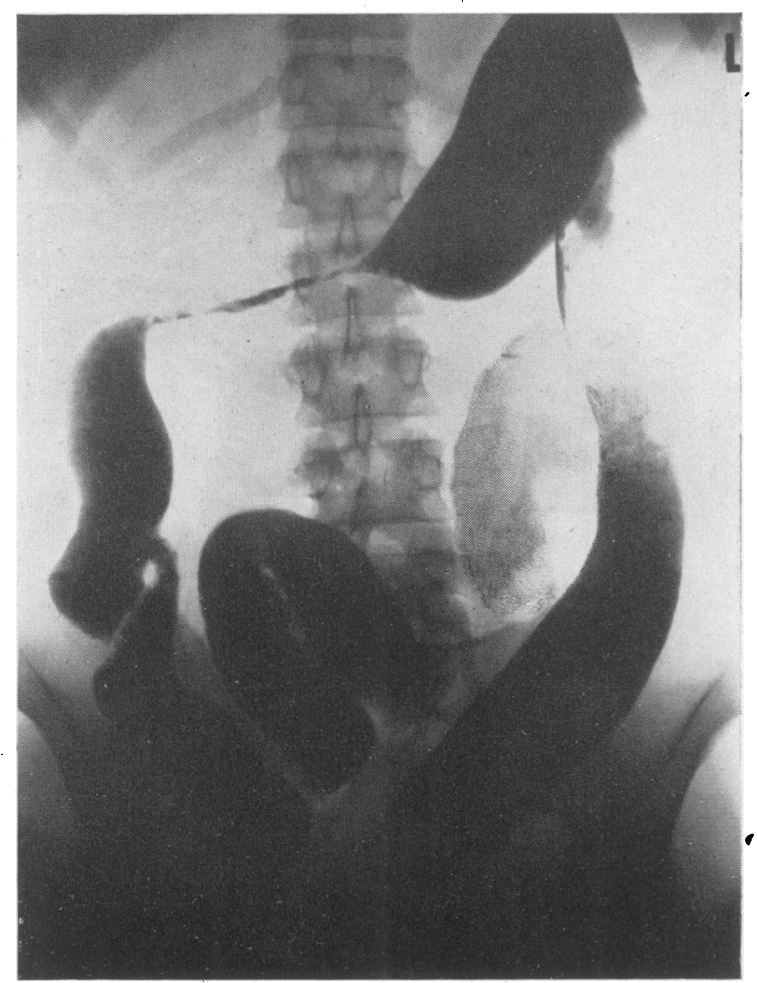

FIG. 32.-Ulcerative colitis with areas of stenosis. 
Chronic Colitis: This simply represents a further stage of the acute colitis, when the bowel is becoming tired, and begins to lose its normal haustral markings and eventually develops that smoothed-out contour, sometimes described as the "gas-pipe" formation of the bowel and is typically demonstrated in Fig. 32 with also areas of permanent stenosis, the result of attempted healing and fibrosis. Perhaps a more frequent variety of colitis is that of the tuberculous variety but not infrequently overlooked, and in all these cases of colitis in which the specific cause has not been determined a radiograph of the chest should be taken (Fig. 33). In many cases on record at St. Mark's Hospital when we have found positive evidence of pulmonary tuberculosis, search for the bacilli in the stools has been undertaken and these found present (Fig. 33).

Sometimes examination of the thorax in cases of colitis reveals unexpected evidence and in Fig. 34 the finding of aortitis radiologically led to the discovery of a positive W.R., and eventually to the diagnosis of a syphilitic colon.

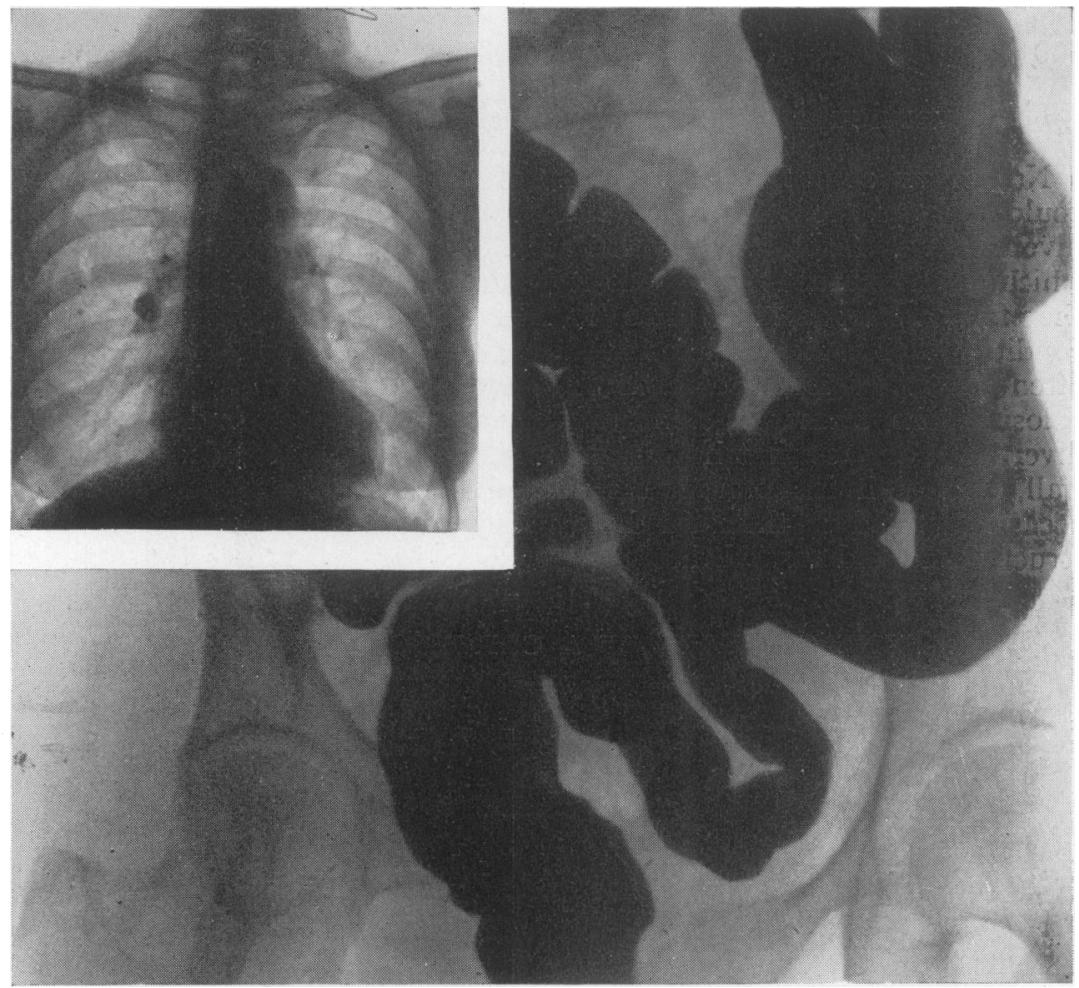

FIG. 33.-Tuberculous colitis. Insert showing foci in the lungs.

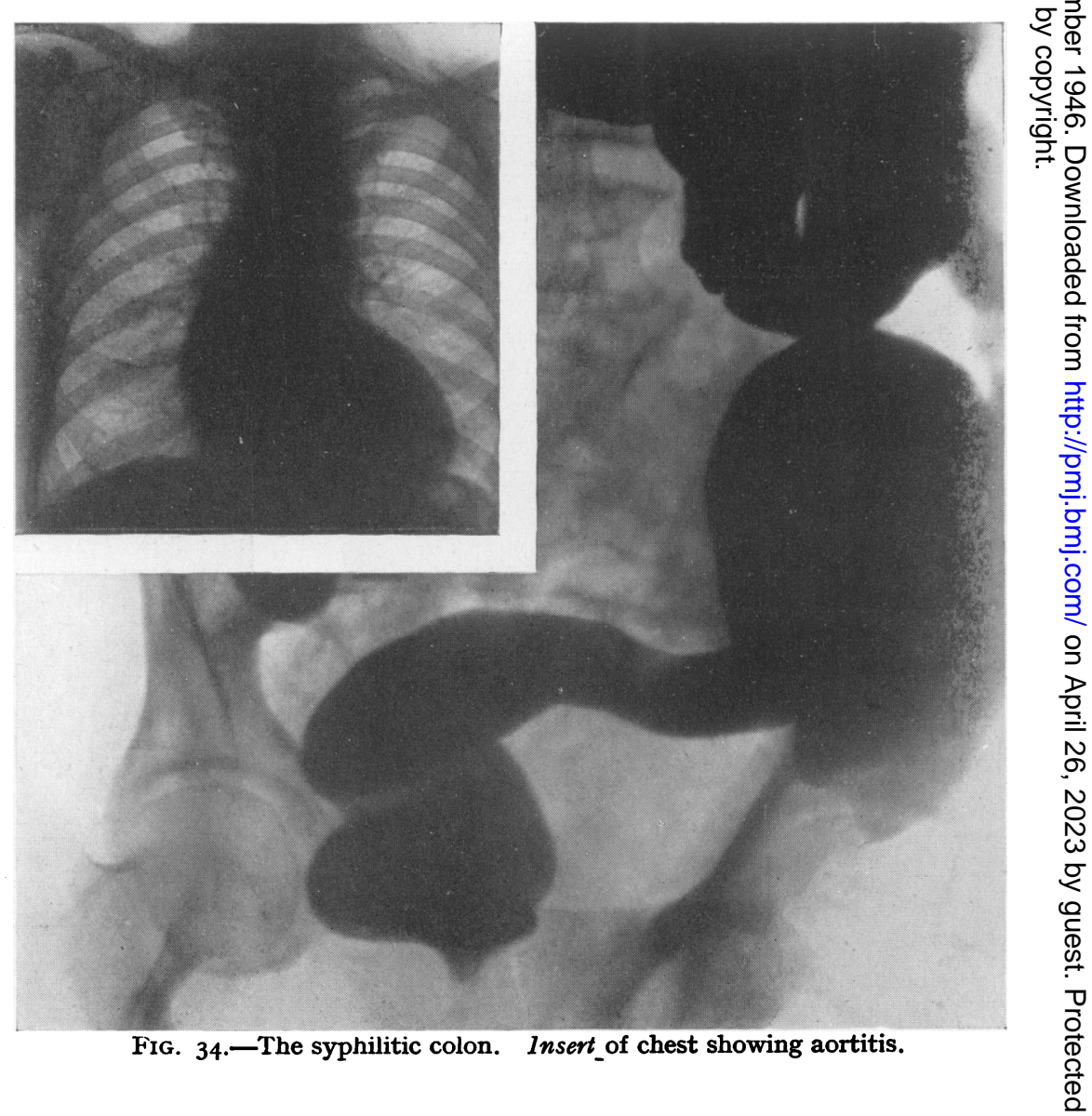




\section{Diverticulosis and Diverticulitis}

No review of pathological lesions of the colon could be complete without diverticulosis and diverticulitis. This, however, is in itself a subject which requires much time to do it justice. Only, therefore, a brief review will be given here of these conditions. First let us differentiate between these often mistaken terms diverticulitis and diverticulosis. The former is simply inflammation of diverticula or sacs that have formed in the bowel wall, and such inflammation can, and does, on occasion spread to the immediate vicinity of the structures in and around these sacs.
Diverticulosis, however, is a term that I prefer to confine to the actual diverticula, or sacs themselves. These sacs are herniated mucosal pouches that appear within or without the bowel wall, depending upon the stage of the disease, and that they are mucosal sacs has to my mind been shown beyond doubt by the fact that they can be blown up like small balloons, when the bowel is inflated with air, and again these sacs deflated when the air is drawn off the bowel, and these appearances recorded radiologically.

As to how these herniated mucosal pouches appear, it would seem that any cause that devitalises the muscle tone of the bowel and so pro-

\section{THE GROWTH OF A CARCINOMA OVER A PERIOD OF THREE YEARS}

1934

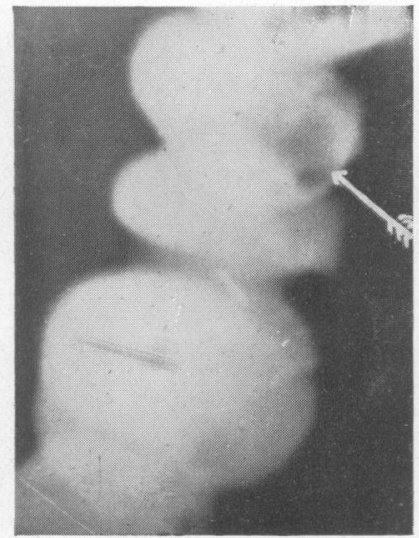

A

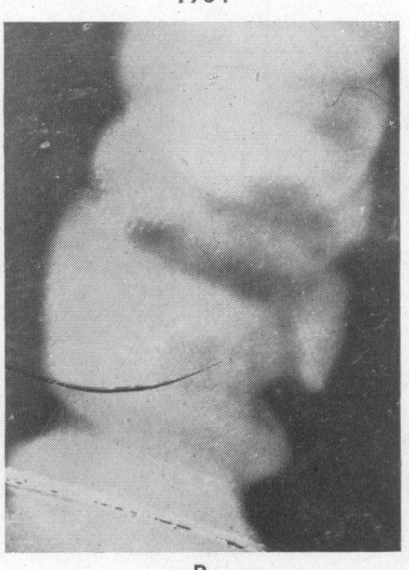

B
1936

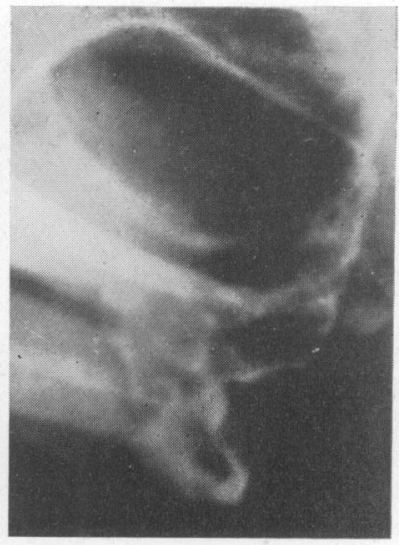

C

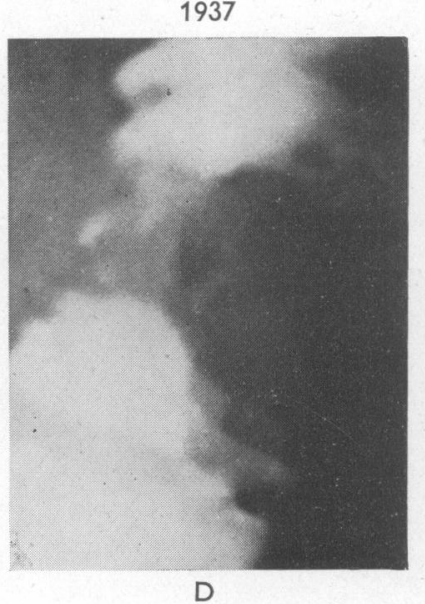

Nine months later.
1937

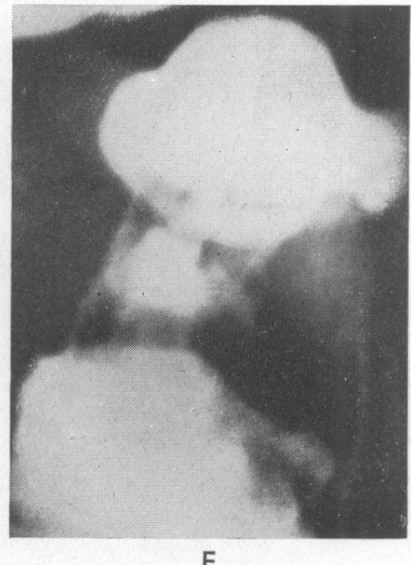

Three months later.

FIG. 35. 
ducing laxity around the spaces for the vessels in the walls, predisposes to sac formation. Therefore looking at the matter broadly some of the main predisposing causes are as follows:-

I. Chronic constipation.

2. Local inflammation in the colon-local colitis.

3. Tumours of the colon.
In connection with tumours of the bowel my original composite figure showing the progress of the growth of an early carcinoma (Fig. 35) from I934 to r937 is included. Running concurrently with this but lower in the colon was evidence of early diverticulosis, and it will be noted in the last radiograph $\mathrm{D}$. I943 that the diverticulosis had

\section{EARLY DIVERTICULOSIS RECORDED OVER A PERIOD OF THREE YEARS}

1934

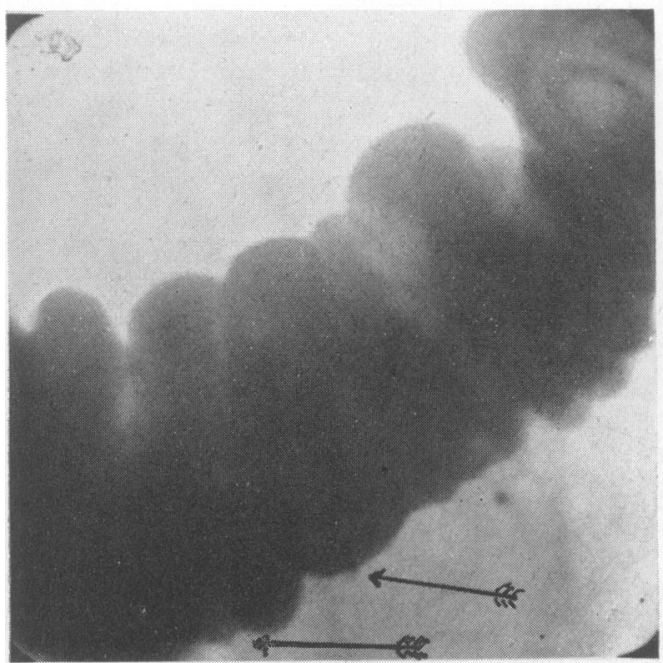

A

First stage. "Ripple-edged" Border. Note the earliest beginnings of local protusions (arrowed) on the crests of some of the ripples.

1937

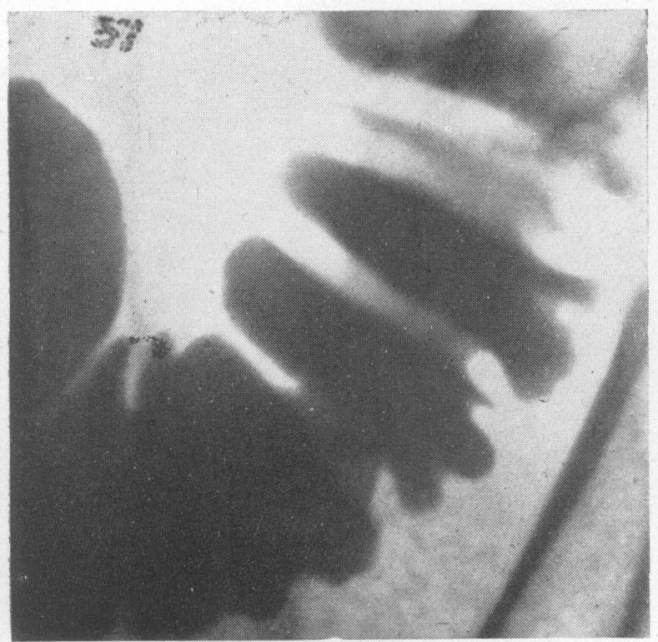

C

After one year's treatment the diverticula have almost gone.
1936

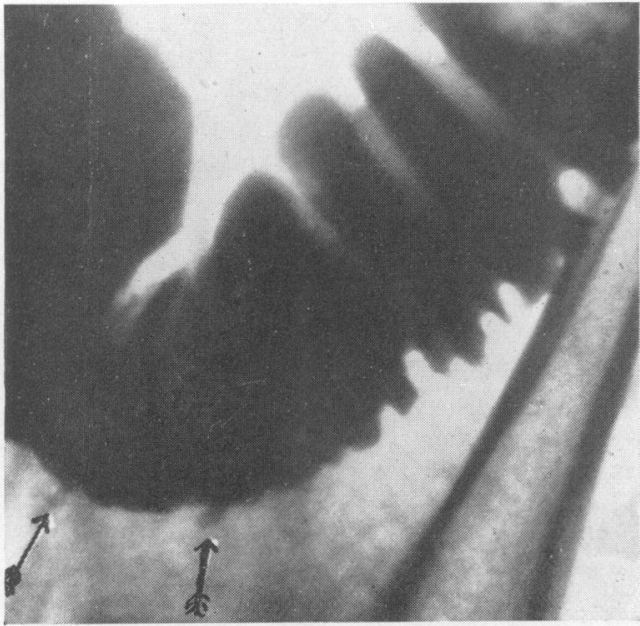

B

Now definite third stage Pulsion Diverticulum.

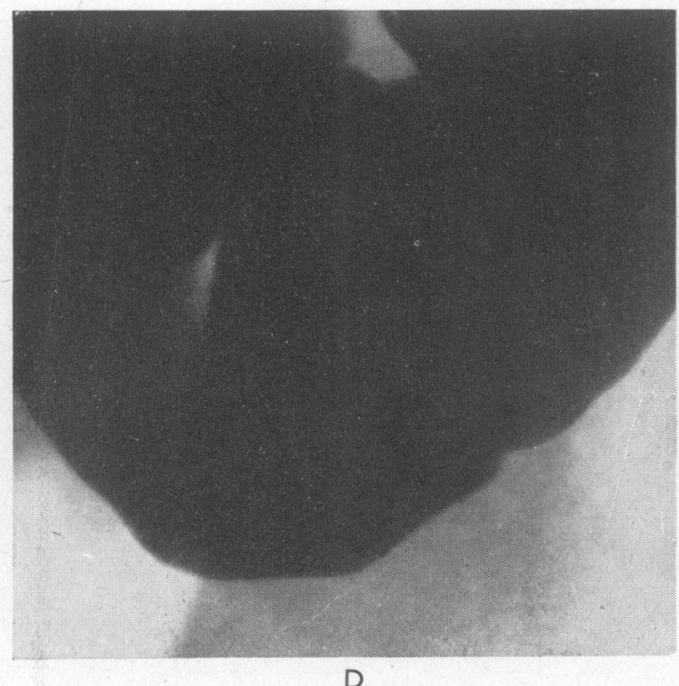

Diverticula disappeared after removal of carcinoma.

FIG. 36 . 
cleared up following removal of the carcinoma, Fig. 36 .

In these cases, it is my view, that the carcinoma is the primary lesion, although perhaps during the first two years of growth undetected radiologically on account of its very small size, but nevertheless causing loss of tone in the colon, and consequently the onset of diverticulosis. The diverticulosis is really a secondary feature, although it may be interpreted as primary, if the early carcinoma is missed.

The case shown in Figs. $37 a$ and $b$, again demonstrates this assumption. The original opaque enema showed what appeared to be a simple $4^{\text {th }}$ stage multiple diverticulosis involving the iliac and pelvic colons, but on examining the same patient some six years later, an opaque enema revealed a large annular growth in the middle of the area where previously only diverticulosis existed. It is therefore now my practice in cases of this nature to advise annual opaque enema examination for the next three to five years, and at the end of that time one can be reasonably sure that the added complication of carcinoma is, or is not to be a danger.

There is also the type of case that produces a

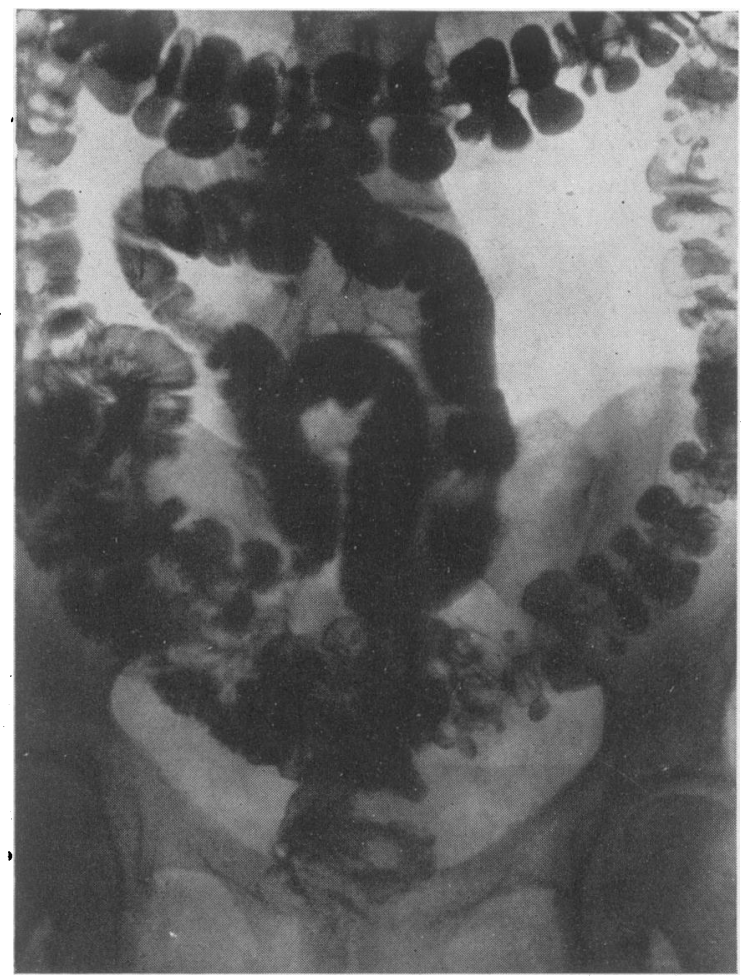

FIG. 37a.-Case showing $5^{\text {th }}$ stage diverticulosis of the iliac and pelvic colons in 1937. filling suggesting only diverticulosis, as shown in Fig. 38. Cases with this appearance where the diverticula are separated and rather spread apart, with the main bowel lumen absent, almost invariably show at operation a combined carcinoma and $5^{\text {th }}$ stage diverticulosis. In the case illustrated a large carcinoma was in the middle of the diverticulosis area.

As to the types of diverticulosis that are met with in the colon I have conveniently classified these into six divisions. The first five stages I have incorporated in a composite diagram (Fig. 39), and also submit individual radiographs (Fig. 40a to $\varepsilon$ ) showing records of actual cases demonstrating most of these stages. The last or 6th stage is that of the fibrosing diverticulitis $(c, d$ and $e)$ The colon that proceeds direct to this stage from the initial inflammatory stage starts laying down fibrous tissue from the beginning, and so no actual diverticula appear at any stage of the disease. The end result resembles a series of coils producing a "roped edge" effect, or the twisted appearance as seen in sugar barley, and this appearance persists throughout, irrespective of air inflation or other pressure from within.

The value of the classification would appear to

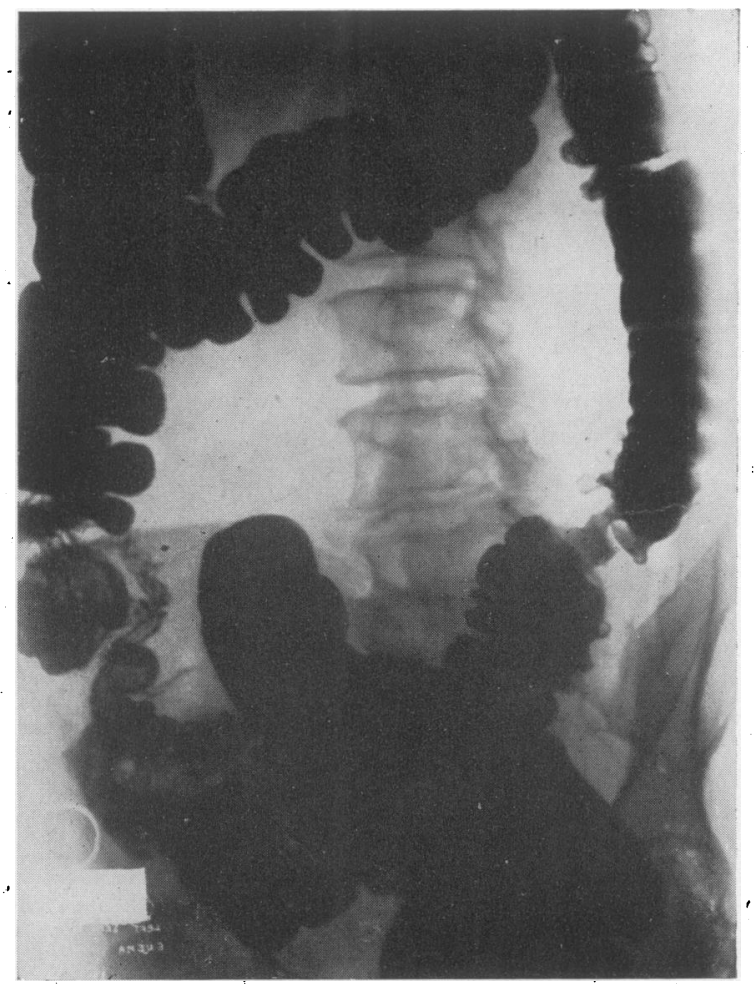

FIG. 37b.-Same patient now examined six years later and in the area of the diverticulosis now a carcinoma present. 


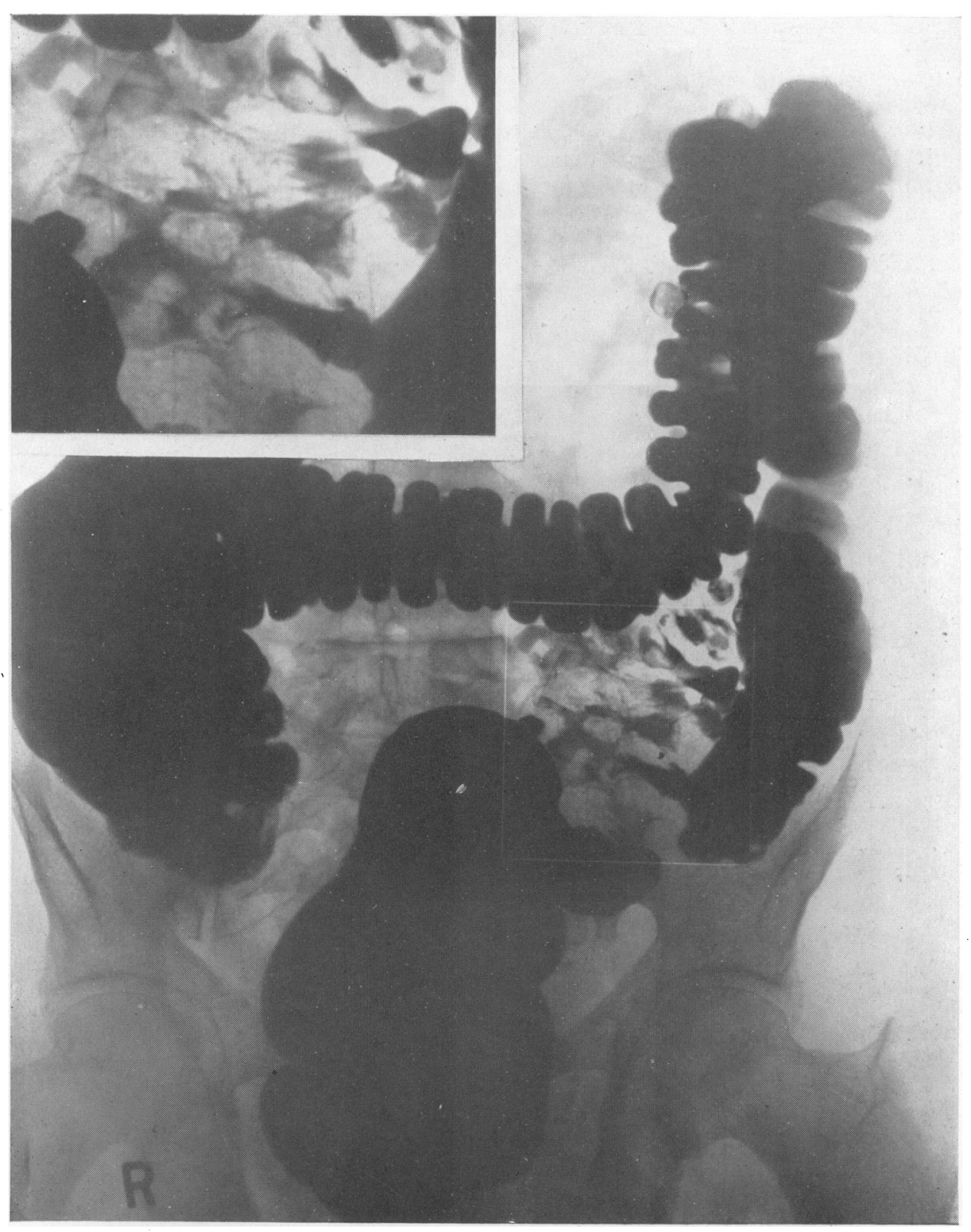

FIG. 38.-A $5^{\text {th }}$ stage diverticulosis of the iliac colon with a carcinoma in the centre of the diverticulosis. 
be as a guide to the clinician in his prognosis and the prospects of success of treatment. Up to the 3rd stage the "Pulsion diverticula," and, possibly, in some of the cases in the 4th stage, "Retractable Ballooning," where the mucosa has still retained its elasticity and exists as a fully movable herniate sac, the outlook is good and the prospects of successful treatment at least hopeful. When, however, the condition has passed into the 5 th Stage"Permanent diverticula" with fibrosed sac walls persisting outside the bowel wall itself, the prospect of cure from treatment is small, if any hope of relief at all can be expected. Likewise in the case of the fibrosing diverticulitis, the results of treatment are not likely to be very effective where the prospect of fibrous contraction and eventually stricture of the area (as shown in Fig. 4I) does not paint a rosy picture, but does emphasise the necessity for diagnosis of the disease in its early stages when active treatment would appear to abort the condition, and so avoid the later and more permanent effects here described.

I wish to record our appreciation to the editors of the British Journal of Radiology for permission to use a number of the illustrations from my original articles, "The Value of the Opaque Enema and its Modifications," May, r944, and "Diverticulitis and Diverticulosis," July, I944, published in the British Journal of Radiology. All the illustrations, however, have been remade and often enlarged.

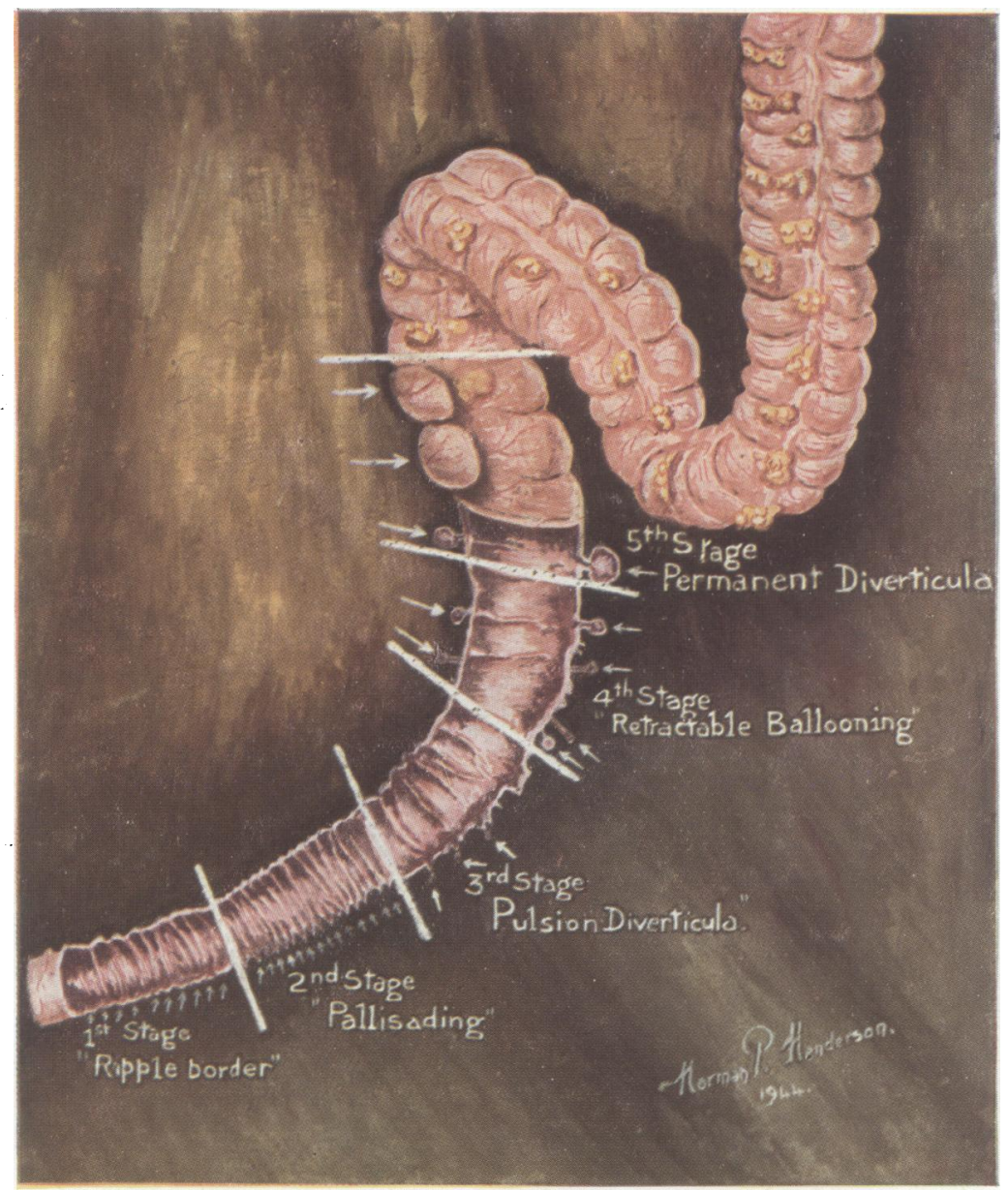

FIG. 39.-Composite diagram of the five stages of diverticulosis. 


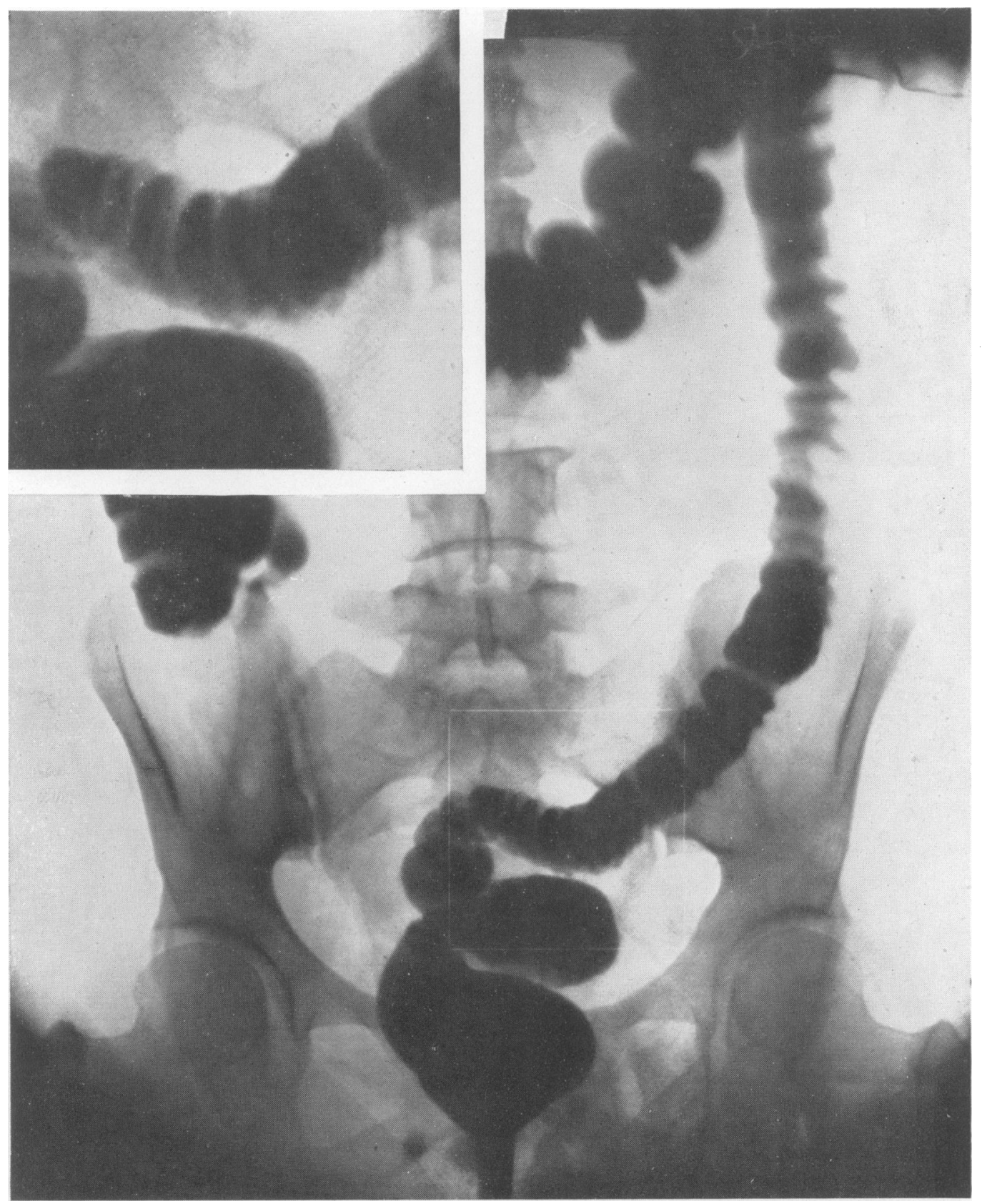

FIG. $40 a$ and insert.-Ist stage "Ripple Border" effect, seen in case examined in 1933. 

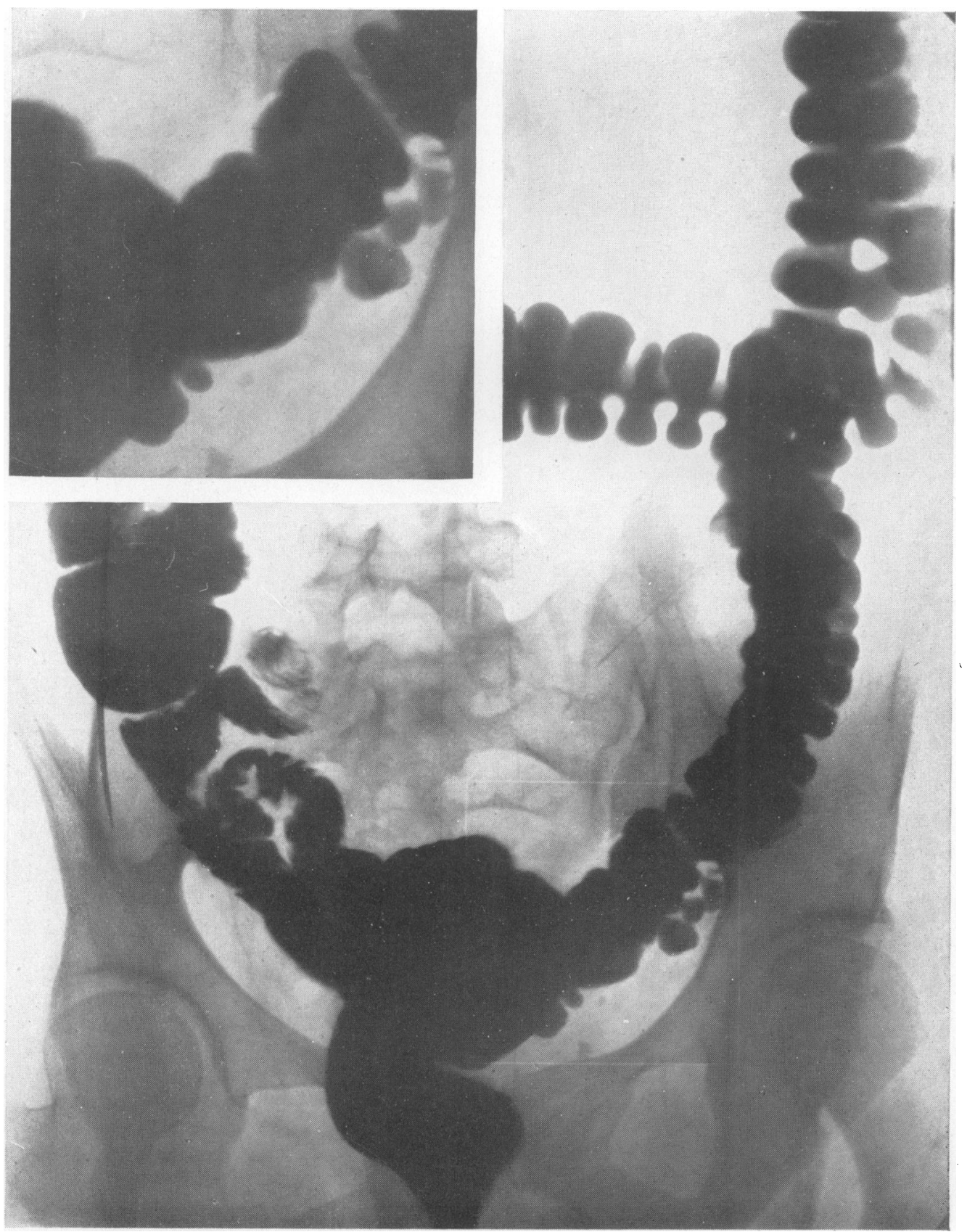

FIG. $4^{\mathrm{o} b}$ and inserl.-Same case in 1943, now $5^{\text {th }}$ stage diverticulosis. 

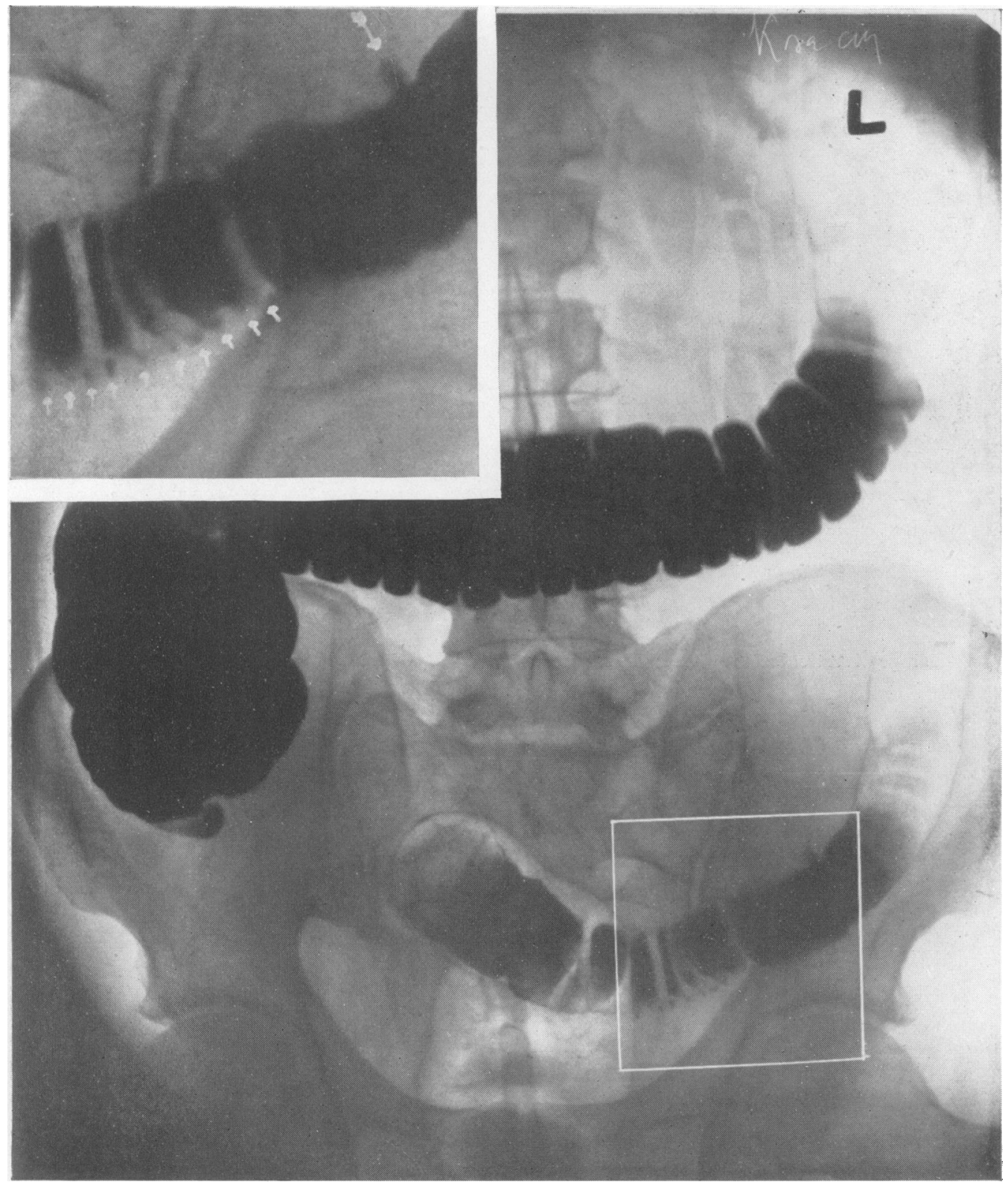

FIG. $40 \mathrm{O}$ and insert.—2nd stage diverticulosis, "Palisading stage."

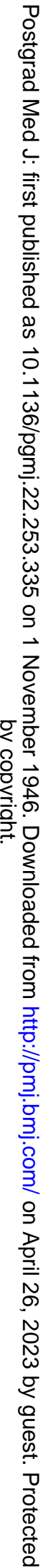




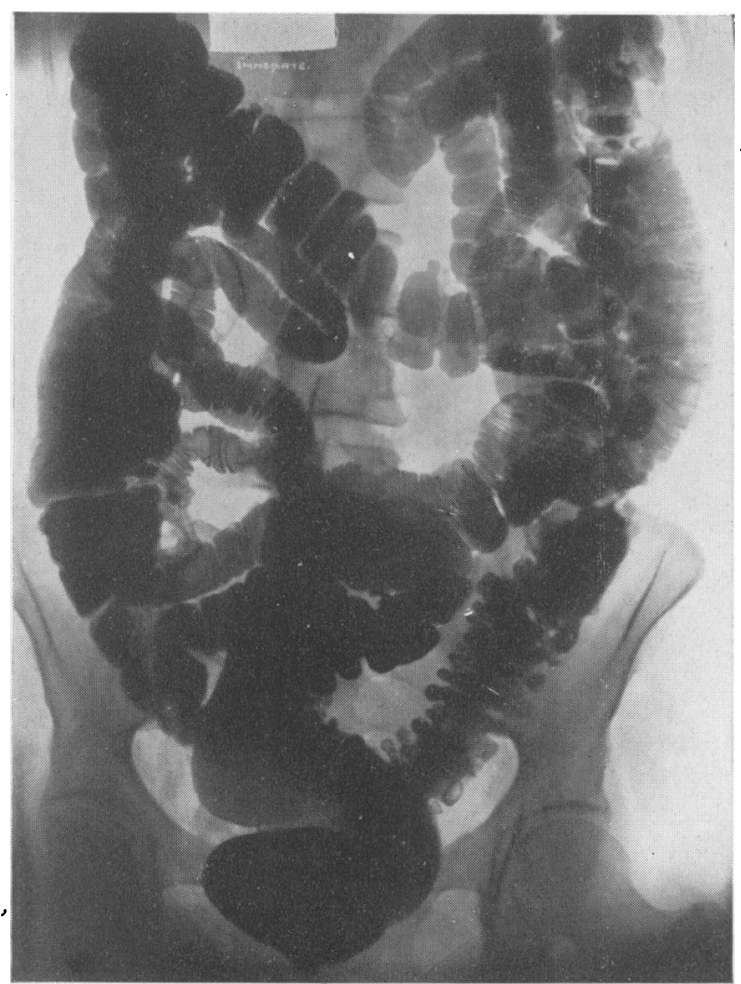

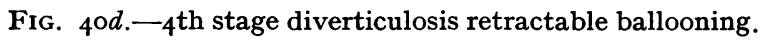

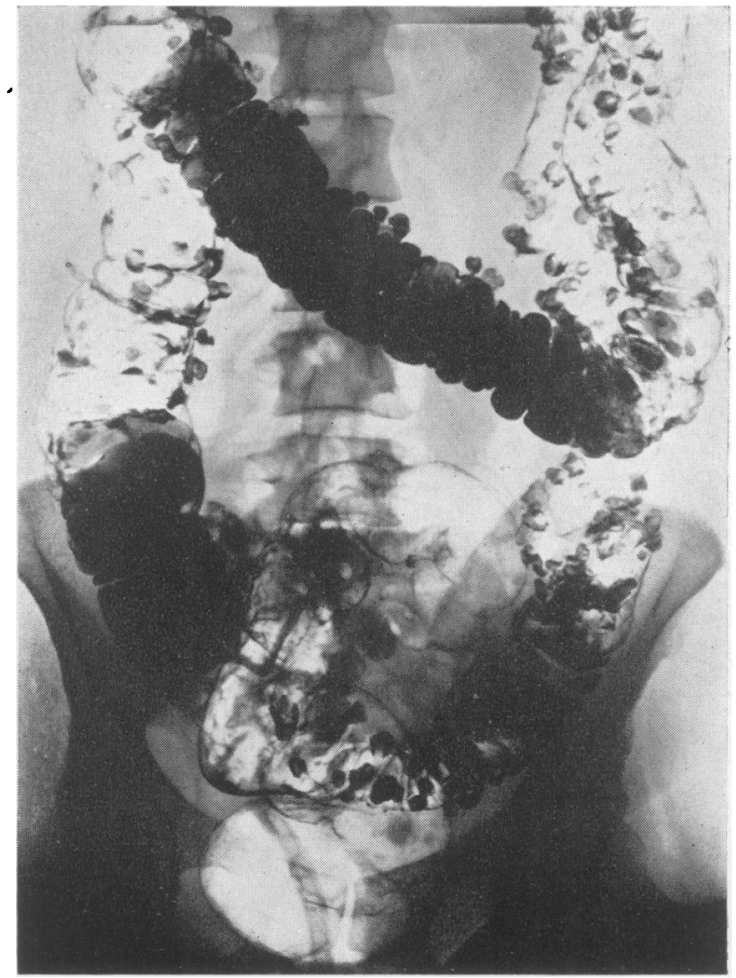

Same case using an inflation technique.

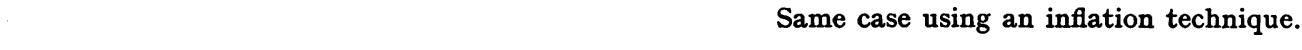




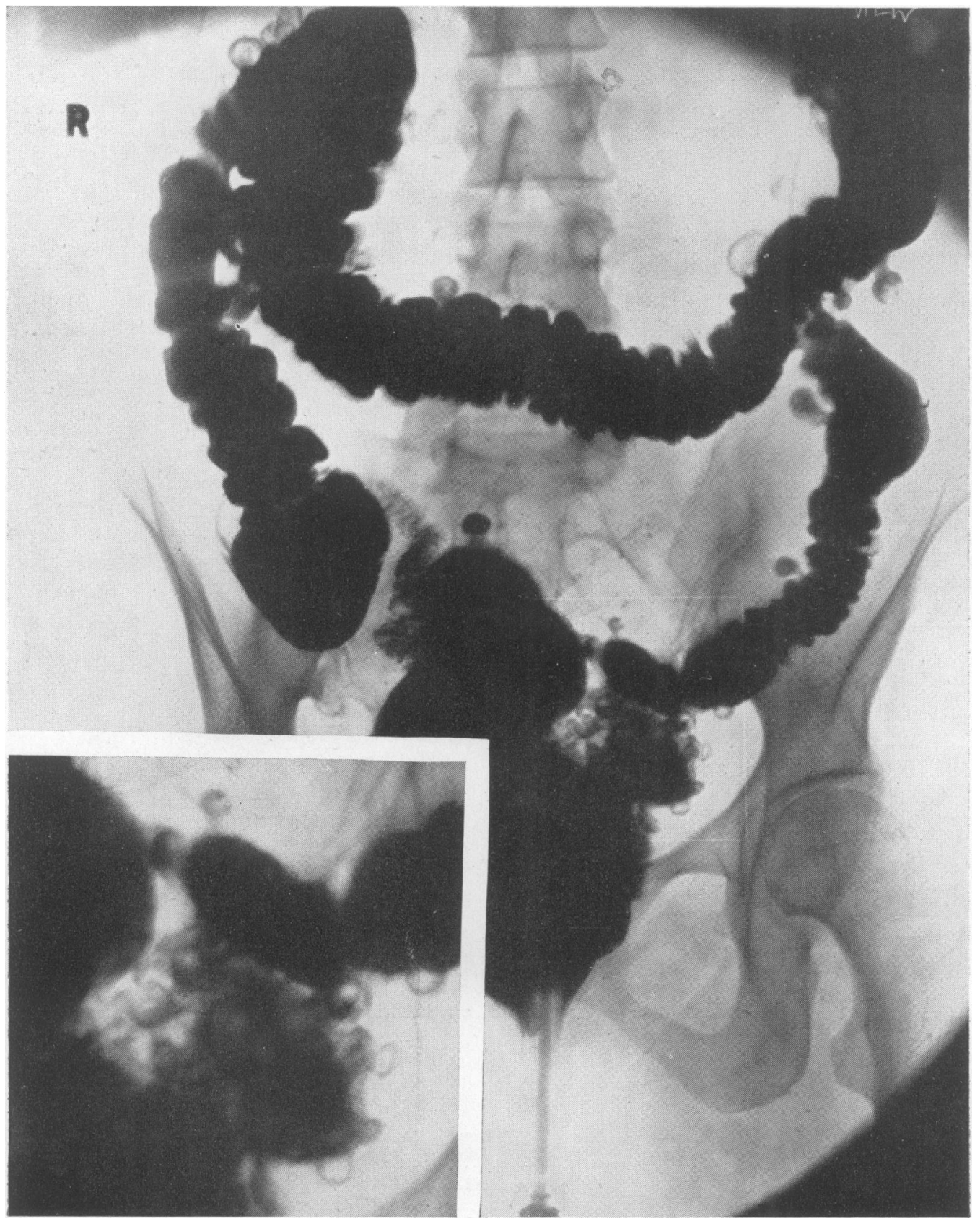

FIG. 40 $e-5^{\text {th }}$ stage diverticulosis-"Permanent diverticula." 


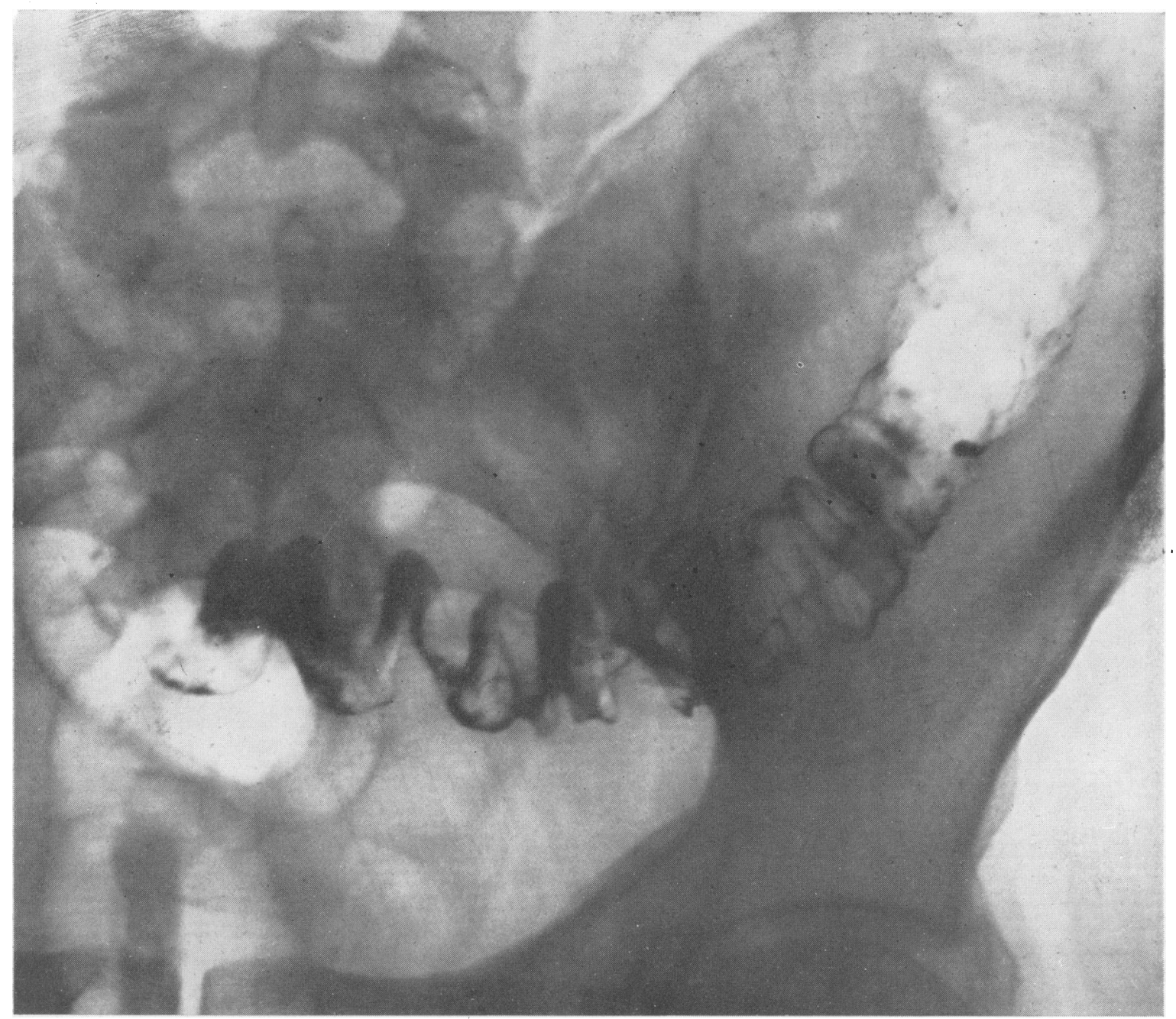

FIG. 4I.-Fibrosing diverticulitis under pressure with air inflation but no relaxation of the colon walls.

\section{REFERENCES}

EDWARDS, H., Proceedings Royal Society of Medicine, Sect. Surgery: Sub-Section of Proct., September 1939, xxxii, No. II, I498.

TESCHENDORF, H. J., Beitrag zur Reliefdiagnostik des DickdarmsFortschr. a. d. Geb. d. Rontgenstr., 1932. xlv, 46-56.

HENDERSON, N. P., Letter, B.M.J., "X-Rays and the Colon," 1943, ii, 247.
HENDERSON, N. P., "St. Mark's X-ray Anti-Incontinence Device,'B.M.J., 1944, ii, 328 .

HENDERSON, N. P., "The Value of the Opaque Enema and its Modifications," B.J.Rad., I944, xvil, I40.

HENDERSON, N. P., "Diverticulitis and Diverticulosis," B.J. Rad., I944, xvii, 197. 